\title{
ONE-SIDED ROCKING ANALYSIS OF CORNER MECHANISMS IN MASONRY STRUCTURES: INFLUENCE OF GEOMETRY, ENERGY DISSIPATION, BOUNDARY CONDITIONS
}

\author{
${ }^{*}$ Linda Giresini ${ }^{1}$, Fabio Solarino ${ }^{2}$, Olivia Paganelli ${ }^{1}$, Daniel V. Oliveira ${ }^{2}$, Maurizio Froli ${ }^{1}$ \\ ${ }^{1}$ Department of Energy, Systems, Territory and Constructions Engineering, University of Pisa, Largo Lucio Laz- \\ zarino, 1, 56100, Pisa, Italy; linda.giresini@unipi.it. \\ ${ }^{2}$ ISISE, Institute of Science and Innovation for Bio-Sustainability (IB-S), Department of Civil Engineering, Uni- \\ versity of Minho, Guimarães, Portugal
}

\begin{abstract}
The corner mechanism in masonry structures is one of the out-of-plane modes that may frequently occur under dynamic actions such as earthquakes. The three dimensional motion, in principle complex to treat, can be simplified into a two-dimensional problem, where a prismatic equivalent block is associated to the corner mechanism. This paper provides a method to treat the corner mechanism in two dimensional rocking analysis, taking into account the roof actions - especially the roof thrust that acts as destabilizing force in the preliminary phases of motion - and the boundary conditions such as the transverse walls. A case study is taken as benchmark to perform rocking non-linear analyses and discuss the role of geometry, energy dissipation and boundary conditions. It is shown the relevant influence of the geometry and of the coefficient of restitution on the stability conditions, whenever the oscillation produce horizontal displacement values of some cm. The results of the case study, subjected to the Central Italy earthquake, are compared to the actual response of the corner mechanism, which collapsed during this seismic swarm, showing that the rocking analysis on the equivalent block correctly predicts the collapse occurred.
\end{abstract}

Keywords: Rocking; corner mechanism; roof thrust; one-sided motion; Housner's model; rigid block; out-of-plane; energy dissipation

\section{INTRODUCTION}

The need of understanding and predict failures due to strong earthquakes, including the overturning of a variety of slender structures, has motivated several studies on the rocking response of rigid blocks. Masonry buildings are strongly influenced by the integrity of the connections between structural elements, both vertical and horizontal, aimed at ensuring the so-called "box effect", often neglected in existing buildings [1]. Weak connections can therefore cause out-ofplane modes involving parts of the structure that can be regarded as rigid blocks [2]. Such out- 
of-plane modes are usually studied through kinematic analysis, based on the limit analysis theorem, involving or not frictional resistances [3,4] or non-linear dynamic analysis, often called rocking analysis [5].

The latter, based on the solution of equations of motion, is able to investigate the performance of elements under earthquakes without neglecting energy dissipation and the response during motion [6,7], that can be subjected to resonance conditions [8]. Recently, several additions in the classical Housner's equation [9] were made to include the presence of sidewalls and tierods horizontally restraining the rocking masonry walls $[10,11]$. When the walls interact with roofs, the overloads and thrusts can also be considered and it was shown that they can be decisive in causing the collapse of these modes [12].

Within the same framework, design strategies and stochastic approaches were proposed to assess the beneficial effect of anti-seismic devices [13,14].

This paper presents a novel procedure to perform rocking analysis applied to masonry corner mechanisms, that occur when one corner of a building is strong enough not to create a vertical crack at the wall intersection [15]. The vulnerability of this mechanism is increased with the destabilizing contribution of the roof and the presence of openings near the edge. Other authors recently investigated this mechanism from experimental and analytical points of view and using non-linear static analysis procedures [16-18].

In this paper, the one-sided motion of a corner mechanism is investigated by analyzing it as single degree of freedom system with spring bed simulating the adjacent walls. The energy dissipation is taken into account with a coefficient of restitution reduced with respect to the analytical one [9], considering recent experimental tests performed on rubble masonry walls [19]. However, it is worth noting that the experimental coefficient of restitution in one-sided rocking is much lower than in two-sided rocking. Whilst in two sided rocking energy damping does not sensitively change with the amplitude rotation, in one-sided rocking energy damping is markedly amplitude-dependent [20]. However, in this paper these effects are neglected and the coefficient of restitution is taken for the sake of safety that associated to two-sided rocking. As for the application of the proposed method, a real case of corner mechanism was selected: that was observed in a school struck by the 2016-2017 Central Italy earthquake in which the corner element collapsed [21]. Section 2 illustrates general and equilibrium considerations about the corner mechanism and the definition of an equivalent prismatic block. Section 3 contains the considerations about the transition between motion phases, considering the effect of the roof overloads, and the equations of motion for the corner mechanism. Section 4 presents the case study and Section 5 illustrates the parametric analysis performed to assess the influence of geometry, boundary conditions and energy dissipation in the dynamic response.

\section{THE CORNER MECHANISM: EQUILIBRIUM CONDITIONS AND DEFINITION OF AN EQUIVALENT PRISMATIC BLOCK}

\subsection{Corner mechanism in masonry structures}

A relevant number of corner mechanism failures was observed in the last Italian earthquakes (Umbria-Marche 1997, L'Aquila 2009, Emilia Romagna 2012, Molise 2002, Figure 1a). These failures are different from simple overturning mechanisms, related to improper connections between vertical walls at the corners. Indeed, the corner mechanisms are originated in presence of good connections between vertical walls at the building corners, but a thrusting roof can cause the formation of a diagonal crack in the two intersecting walls bypassing the corners themselves. 
The interaction of masonry structures with roofs is extremely relevant under dynamic actions such as earthquakes. Such an interaction should not be neglected particularly for existing masonry buildings, which usually have timber roofs composed by king-post trusses or beams, and completed by steel or wooden purlins and rafters [22]. The motion, and consequently the stability of the corner mechanism, strongly depends on this interaction. Starting from the essential role of the additional mass due to the roof, which changes the evolution of motion in the rocking mechanism, another crucial effect is caused, as pointed out, by a thrusting action. This applies a destabilizing effect in the motion, easing the out-of-plane behavior of the masonry corner in contact with the roof. A generic corner mechanism involving two intersecting walls of thickness $s_{1}$ and $s_{2}$, and height $\mathrm{h}$, one with a window and the second one without it, can be defined in principle by three angles $\alpha, \beta$ and $\eta$ (Figure 1b). The main axes are in the main direction of the building, $\mathrm{X}$ and $\mathrm{Y}$, and the out-of-plane rotation axis is $\omega$.

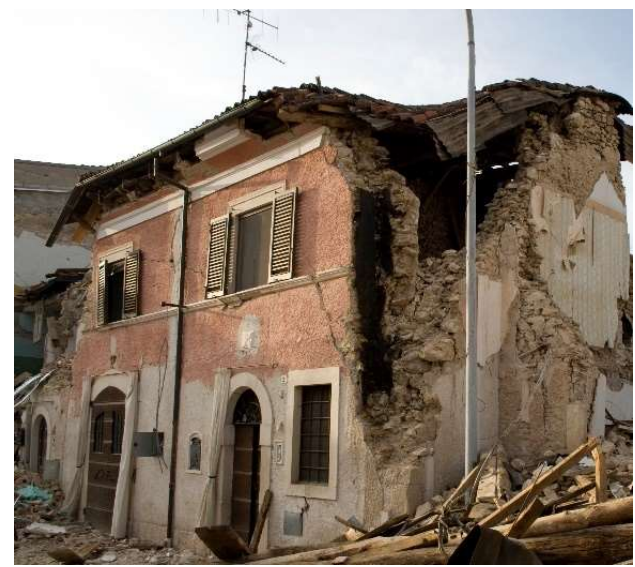

(a)

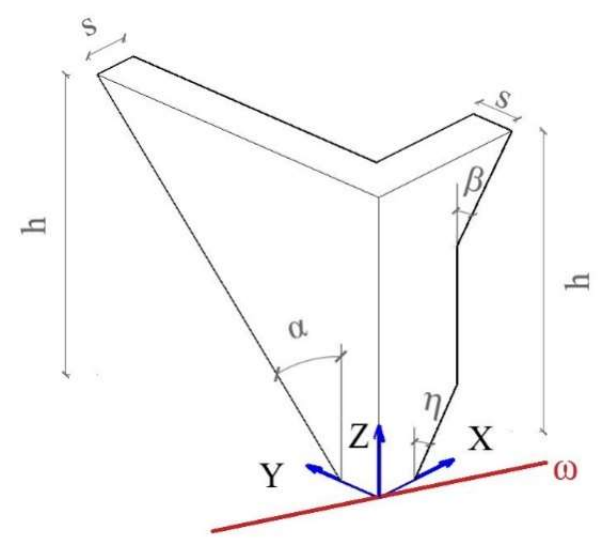

(b)

Figure 1: Corner mechanism: example in a real masonry building (L’Aquila 2009) (a), and schematic view (b).

\subsection{Definition of the equivalent prismatic block}

The corner wall portion is composed by two intersecting walls, in general with different thickness and one opening to generalize the problem, subjected to the roof overload (Figure 2a). The motion of the corner mechanism is in principle in three dimensions and rotates around the corner point $O$ (Figure 2Errore. L'origine riferimento non è stata trovata.). For the sake of simplicity, this $3 \mathrm{D}$ problem can be simplified into a two-dimensional problem, associating the corner geometry to a prismatic equivalent block.

The equivalence criterion consists in keeping the same center of mass $G$ in the original position and the same moment of inertia $I$; indeed, $G$ and $I$ are two crucial parameters influencing the dynamic response of the rigid block [23]. To state the equivalence, first the roof configuration has to be studied, by identifying the inertia masses participating to the motion.

A straightforward method to take into account the roof loads regards the assumption of a system of lumped masses. Let one assume the general configuration displayed in Figure 2: one of the wall composing the corner has an opening and the other one is full. Both walls are characterized by linearly vertical, distributed overloads and their resultants are punctual loads in points A, B, C (Figure 2a). On A, also the horizontal thrust of a strut, if any, can be considered.

Afterwards, the first step to obtain the equivalent block consists in calculating the center of mass $\mathrm{G}_{1}$ of the corner including the contribution of the roof loads. Similarly, $\mathrm{G}_{0}$ is the center of mass of the corner without additional roof masses (Figure $2 b$ ). The application points A, B, C 
of the roof loads coincide with the floor height $h$, and these positions are considered in the equation of motion, not to change their effect in the equivalent configuration. They are identified by an angle $\alpha_{i}$ from the vertical block line and a corresponding radius vector that connects the pivot point $\mathrm{O}$ to the mass position $R_{i O}$. These geometric parameters are very useful in synthetically writing the differential equation of motion (illustrated in $\S 3.2$ ). At this stage, it is possible to define the inclination of the generic $\omega$ rotation axis of the hinge in point $O$, that is orthogonal to the plan defined by $\mathrm{Z}$ axis and line $\mathrm{OG}_{1}$ or $\mathrm{OG}_{0}$ depending on whether the additional roof masses are considered or not. It is worth noting that the rotation plan strictly depends on the geometry and on the equilibrium conditions [16,17].

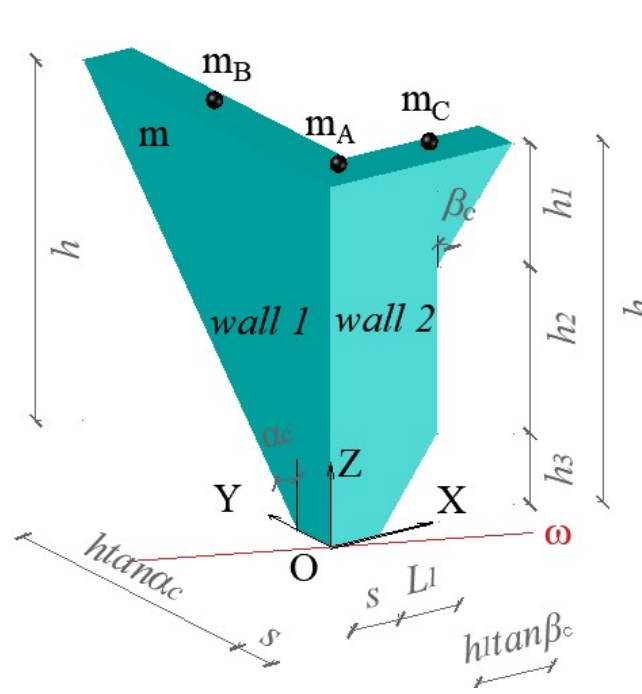

(a)

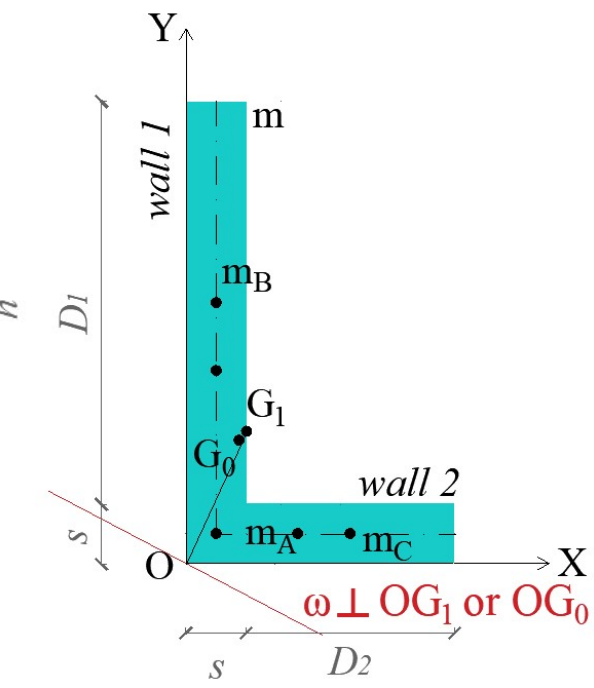

(b)

Figure 2: 3D view of the corner mechanism (a) and in-plan view (b) with the indication of the roof masses.

Once that the rotation axis is known, the corresponding moment of inertia is:

$$
I_{\omega}=\frac{I_{X, 1}+I_{Y, 1}}{2}+\frac{I_{X, 1}-I_{Y, 1}}{2} \cos \gamma-I_{X Y, 1} \sin \gamma
$$

where $\gamma$ is the angle formed by the Y main building direction and the orthogonal line to the $\omega$ axis (Figure 2b). In Eq. (1)Errore. $L$ 'origine riferimento non è stata trovata. $I_{X, 1}$ and $I_{Y, 1}$ are the inertia moments related to Phase 1 (namely the configuration with the additional roof masses, defined in \$2.2). The other inertia moments referred to Phase 2 are reported in Appendix A. Phase 1 and 2 are shown in detail in Section 3.

In general, one can imagine to make the rotation axis to correspond with one of the main building axes, $\mathrm{X}$ or $\mathrm{Y}$, and obtain the equivalent prismatic block thickness $s_{e q}$ (Figure 3 ) by doubling the distance of $\mathrm{G}_{1}$ (or $\mathrm{G}_{0}$ ) from the $\omega$ rotation axis. The equivalent height is then calculated 
from the inertia moment with respect to the considered (modified) axis. In this way the inertial properties of the rocking corner are preserved and the equivalence is guaranteed.

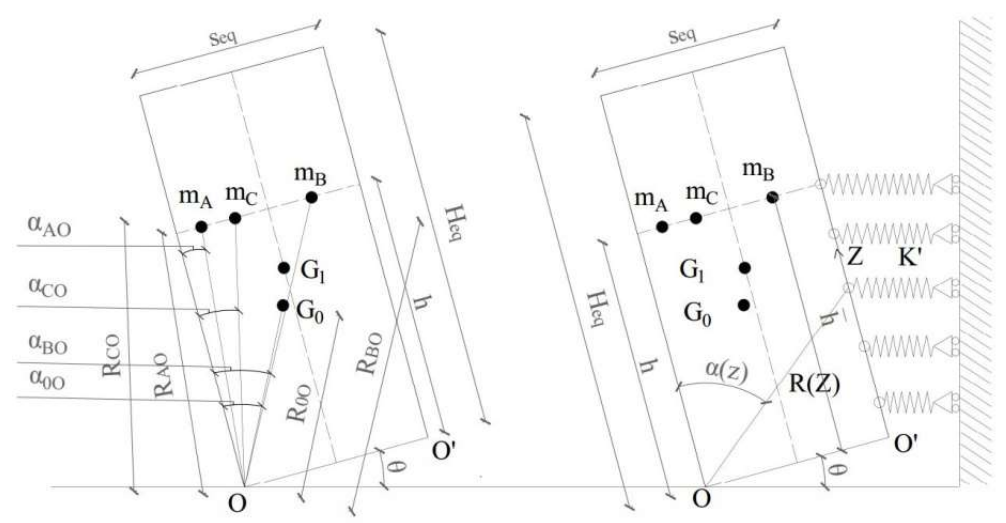

Figure 3: The equivalent prismatic block with horizontal elastic restraint and roof masses.

For instance, in Figure 4, the equivalent block thickness is obtained by doubling the X-coordinate of the center of mass, and calculating the equivalent height from the inertia moment with respect to $\mathrm{Y} \equiv \omega$. Obviously, the analysis of the corner with respect to $\mathrm{O}$ and $\mathrm{O}$ ' (Figure 3) requires the construction of two equivalent models in the two main building directions, applying the equation of motion illustrated in the Section 3.

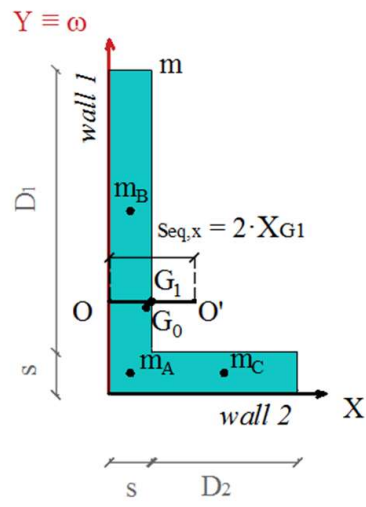

Figure 4: Geometry of the overturning with rotation around $\mathrm{Y}$ axis.

\section{DYNAMICS OF THE CORNER MECHANISM}

\subsection{Phases of motion}

In the rocking motion of the corner mechanism two phases can be distinguished:

- Phase 1: the block starts to rock from the base corner $\mathrm{O}$ to $\mathrm{O}^{\prime}$ due to the contribution of the masonry wall and the roof loads (Figure 3);

- Phase 2: once that a threshold horizontal displacement of the rocking corner is attained, by assuming that the roof stands in its position, the contact between masonry corner and roof is not guaranteed anymore. In this phase only the masonry corner mechanism is considered neglecting the contribution of the roof loads.

In Phase 1 , the center of mass $\mathrm{G}_{1}$ and the moment of inertia $I_{1}$ are obtained by the contribution of masses $m, m_{A}, m_{B}, m_{C}$ (Eq. (A.1) and (A.4) in Appendix A). 
In Phase 2, the contribution on the center of mass $\mathrm{G}_{0}$ and on the moment of inertia $I_{0}$ (Eq. ( (A.2) and (A.3) in Appendix A) are only due to the masonry portion, and therefore to the mass $m$.

These parameters and the corresponding inertia moments are used in the equation of motion, defined in the following paragraph, and a specifically developed MATLAB code [24] automatically recognizes the passage from phase 1 to phase 2 , accordingly updating the geometric and mechanical parameters.

\subsection{Equation of motion of the corner mechanism}

The equation of motion of a block horizontally restrained and subjected to additional masses $m_{i}$ and horizontal thrust $H_{r}$ is:

$$
\begin{aligned}
& I_{\omega} \cdot \ddot{\vartheta}+\sum_{i} \operatorname{sgn}(\vartheta) \cdot m_{i} \cdot g \cdot R_{i} \cdot \sin \hat{A}_{\vartheta, i}-\sum_{i} m_{i} \cdot R_{i} \cos \hat{A}_{\vartheta, i} \cdot \ddot{u}_{g} \cdot g+\operatorname{sgn}(\vartheta) \cdot K^{\prime} \cdot \bar{h} \cdot\left(\hat{A}+\frac{\hat{B} \cdot \bar{h}}{2}+\frac{\hat{C} \cdot \overline{h^{2}}}{3}\right)+ \\
& +\operatorname{sgn}(\vartheta) \cdot K \cdot R_{t}^{2} \cdot \cos \hat{A}_{t} \cdot\left[\sin \alpha_{t}-\sin \hat{A}_{t}\right]-H_{r} \cdot R_{r} \cdot \cos \hat{A}_{r}=0
\end{aligned}
$$

Where $\hat{A}_{\vartheta, i}=\alpha_{i}-\operatorname{sgn}(\vartheta) \vartheta, \hat{A}_{r}=\alpha_{r}-\operatorname{sgn} \vartheta(\vartheta), \hat{A}_{t}=\alpha_{t}-\operatorname{sgn} \vartheta(\vartheta)$,

$$
\hat{A}=\operatorname{sgn}(\vartheta) \cdot s^{2} \cdot \sin \vartheta \cdot \cos \vartheta \cdot(1-\cos \vartheta), \hat{B}=s \cdot\left(\sin ^{2} \vartheta \cdot \cos \vartheta-\cos ^{3} \vartheta+\cos ^{2} \vartheta\right) \text {, }
$$

$\hat{C}=\operatorname{sgn}(\vartheta) \cdot \sin \vartheta \cdot \cos ^{2} \vartheta$. The position of the additional masses due to the roof is defined by $\hat{A}_{\vartheta, i}$, whereas the basic geometric dimensions $\bar{h}$ and $s$ are respectively the effective height of the spring bed and the thickness of the equivalent prismatic block, obtained with the methodology expressed in $\S 2.2$. In the equation of motion, the term $H_{r}$ is the roof thrust; its direction and magnitude can be assumed constant during motion in the hypothesis of small displacements [12].

The term depending on $K$ in Eq. (2) represents the contribution of a possible tie-rod, whose position is identified by $R_{t}$. The corner wall is also restrained by horizontal diaphragms and transverse walls, that are represented as springs connected to the block (Figure 3). One can choose to simulate these boundary conditions as spring beds with unitary stiffness, both in tension and in compression. In general, the rocking analysis specialized for masonry mechanisms should consider one-sided motion (1S), namely a motion in which the two values of unitary stiffnesses of the spring beds in tension and in compression are different. In this paper, the analysis is performed considering the $1 \mathrm{~S}$ motion and, for the sake of simplicity, the spring bed only in compression. For cantilever walls, the compression stiffness is calculated as $K^{\prime}=$ $E s_{t} / L$, where $\mathrm{E}$ is the masonry elastic modulus in horizontal direction, $s_{t}$ the transverse wall thickness (to double if the number of sidewalls is 2 ), and $L$ is the effective depth of the transverse walls [10].

As for the corner mechanism, two restraints of different direction are identified: one of wall 1 in $\mathrm{Y}$ direction and the second of wall 2 in X direction, as shown in Figure 5. To obtain a significant stiffness considering the rotation around the $\omega$ axis, the stiffness in $\mathrm{X}$ and $\mathrm{Y}$ direction is calculated with the following expression (Figure 6):

$$
\begin{aligned}
K_{X}^{\prime} & =\frac{E_{X} \cdot s p}{(\bar{A}+\bar{B}+\bar{C}) / 3} \\
K_{Y}^{\prime} & =\frac{E_{Y} \cdot s p}{\bar{D}}
\end{aligned}
$$


Where $\bar{A}=\frac{L_{A, i}}{2} ; \bar{B}=\frac{L_{B, i+} L_{B, s}}{2} ; \bar{C}=0 ; \bar{D}=\frac{L_{D, i}}{2}$ (Figure 6).

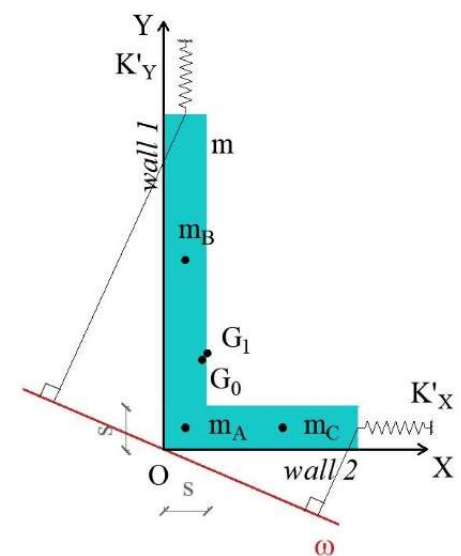

Figure 5: Geometry of the corner mechanism with spring beds simulating the adjacent walls.

These are the average lengths of each adjacent wall, considering the opening in wall along the $\mathrm{X}$ direction that does not contribute.
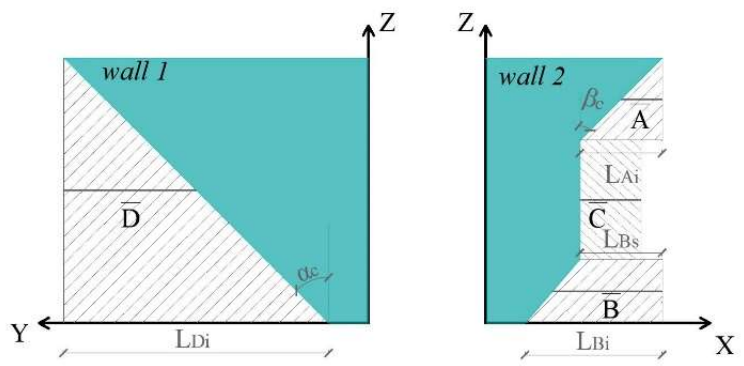

Figure 6: Calculation of the effective lengths of the walls adjacent to the corner block for the definition of the compression spring bed stiffness.

Depending on the rotation axis $\omega$, the value of the spring bed stiffness has to be evaluated. For instance, if the rotation occurs around the $\mathrm{Y}$ axis $(\omega \equiv Y)$, then only the $K_{X}^{\prime}$ stiffness has to be considered, and viceversa for the rotation around $\mathrm{X}$ axis $(\omega \equiv X)$.

\section{APPLICATION OF THE METHODOLOGY TO A CASE STUDY}

\subsection{Case study}

The case study selected in this paper to apply the methodology is a corner mechanism activated during the 2016-2017 Central Italy earthquake in a two storey T-shape masonry building (Figure 7). A 3D finite element model of the entire building have previously been developed by Ferrero et al. [25] who accurately predicted the global in-plane cracks actually observed. The local corner mechanism, however, was not possible to obtain from such numerical model due to the presence of the concrete bond-beam and to the possible disintegration of the material. The earthquake was characterized by a seismic swarm lasted about five months, from August 2016 to January 2017. The first relevant shock was recorded on August $24^{\text {th }}$, with magnitude 6.0 , but the strongest one was on October $30^{\text {th }}$ (moment magnitude 6.5), just few days after two earthquakes in October $26^{\text {th }}$ (moment magnitude 5.4 in the morning and 5.9 in the evening). 
The corner mechanism was likely formed during the first relevant shock in August, but the collapse occurred on October $26^{\text {th }}$.

The masonry is made of irregular square stone and the floors are concrete slabs, with the exception of the last floor made of steel beams and clay elements to lighten the structure. The roof is made of timber with two or three courses of purlins resting on load-bearing walls and, in correspondence of the hips, wooden struts; the latter are pushing on the cantonal one at the height of the perimeter reinforced concrete curb. The roof is considered acting on the masonry corner applying an outward thrust, as specified in the next paragraph.

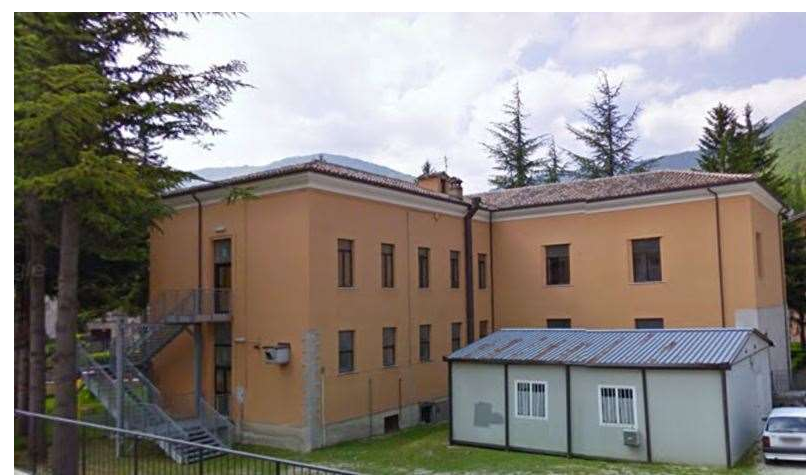

(a)

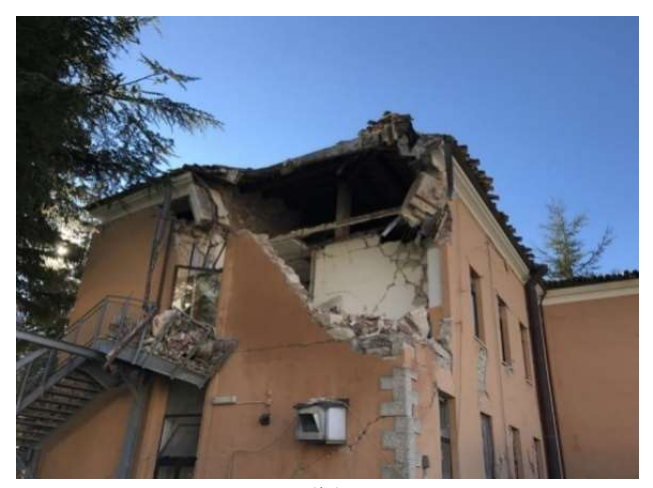

(b)

Figure 7: The corner mechanism activated in a masonry building during the 2016 Central Italy earthquake.

\subsection{Geometric and mechanical features of the corner mechanism}

The adopted geometric parameters of the equivalent prismatic block and of the roof masses, calculated through the procedures illustrate in $\S 2.2$, are listed in Table 1.

\begin{tabular}{|c|c|c|c|c|c|c|c|c|c|c|c|}
\hline \multicolumn{4}{|c|}{$\begin{array}{c}\text { Geometric parameters for the } \\
\text { equivalent block }\end{array}$} & \multicolumn{8}{|c|}{ Geometric parameters for roof masses and mechanical parameters } \\
\hline & aroundY & aroundX & & & aroundY & aroundX & & & aroundY & aroundX & \\
\hline $\mathrm{Seq}_{\mathrm{eq}}$ & 1.308 & 2.864 & $\mathrm{~m}$ & $\mathrm{R}_{0 \mathrm{O}}$ & 2.793 & 3.042 & $\mathrm{~m}$ & $\mathrm{R}_{\mathrm{BO}}$ & 4.362 & 5.187 & $\mathrm{~m}$ \\
\hline $\mathrm{H}_{\mathrm{eq}}$ & 6.199 & 6.342 & $\mathrm{~m}$ & $\alpha_{0 O}$ & 0.207 & 0.454 & $\mathrm{rad}$ & $\alpha_{\mathrm{BO}}$ & 0.075 & 0.576 & $\mathrm{rad}$ \\
\hline $\mathrm{R}_{\mathrm{eq}}$ & 3.410 & 3.640 & $\mathrm{~m}$ & $\mathrm{R}_{0 \mathrm{O}}$ & 2.830 & 3.132 & $\mathrm{~m}$ & $\mathrm{R}_{\mathrm{BO}}$ & 4.460 & 4.350 & $\mathrm{~m}$ \\
\hline$\alpha_{\mathrm{eq}}$ & 0.193 & 0.404 & $\mathrm{rad}$ & $\alpha_{00}$ & 0.263 & 0.510 & $\mathrm{rad}$ & $\alpha_{\mathrm{BO}}$ & 0.222 & 0.009 & $\mathrm{rad}$ \\
\hline $\mathrm{K}^{\prime}$ & $1.57 \mathrm{E} 9$ & $5.49 \mathrm{E} 8$ & $\mathrm{~N} / \mathrm{m}^{2}$ & $\mathrm{R}_{\mathrm{AO}}$ & 4.362 & 4.362 & $\mathrm{~m}$ & $\mathrm{R}_{\mathrm{CO}}$ & 4.698 & 4.362 & $\mathrm{~m}$ \\
\hline $\mathrm{e}$ & 0.945 & 0.771 & & $\alpha_{\mathrm{AO}}$ & 0.075 & 0.075 & $\mathrm{rad}$ & $\alpha_{\mathrm{CO}}$ & 0.387 & 0.075 & $\mathrm{rad}$ \\
\hline $\mathrm{X}_{\mathrm{G} 1}$ & \multicolumn{2}{|c|}{0.654} & $\mathrm{~m}$ & $\mathrm{R}_{\mathrm{AO}}$ & 4.460 & 5.037 & $\mathrm{~m}$ & $\mathrm{R}_{\mathrm{CO}}$ & 4.375 & 5.037 & $\mathrm{~m}$ \\
\hline $\mathrm{Y}_{\mathrm{G} 1}$ & \multicolumn{2}{|c|}{1.432} & $\mathrm{~m}$ & $\alpha_{\mathrm{AO}}$ & 0.222 & 0.528 & $\mathrm{rad}$ & $\alpha_{\mathrm{CO}}$ & 0.107 & 0.528 & $\mathrm{rad}$ \\
\hline $\mathrm{Z}_{\mathrm{G} 1}$ & \multicolumn{2}{|c|}{3.346} & $\mathrm{~m}$ & $\mathrm{Hr}$ & \multicolumn{2}{|c|}{1870} & $\mathrm{~N}$ & $\mathrm{I}_{\omega}$ & 499030 & 601954 & $\mathrm{~kg} \mathrm{~m}^{2}$ \\
\hline
\end{tabular}

Table 1: Geometric and mechanical parameters for the equivalent block

Due to the eccentricity of the masses, the radius vector and the slenderness ratio change depending on the rotation sign, $\mathrm{R}_{\mathrm{iO}}$ or $\alpha_{\mathrm{iO}}$ for clockwise and $\mathrm{R}_{\mathrm{iO}}$ ' or $\alpha_{\mathrm{iO}}$ ' for counterclockwise rotation. 


\subsection{Selection of the acceleration time histories}

The seismic events of interest for the selected case study are those occurred on August $24^{\text {th }}$, on October $26^{\text {th }}$ and $30^{\text {th }} 2016$.

The seismic records are provided by accelerometer sensors at the hinge level, corresponding to the first floor of the building (Figure 8), installed after the seismic swarm was initiated in August 2016. This aspect is of particular relevance, since it is not necessary to filter the seismic records at the ground level, process that usually cause unacceptable errors in the assessment of the correct seismic input at a certain level $\mathrm{Z}$.

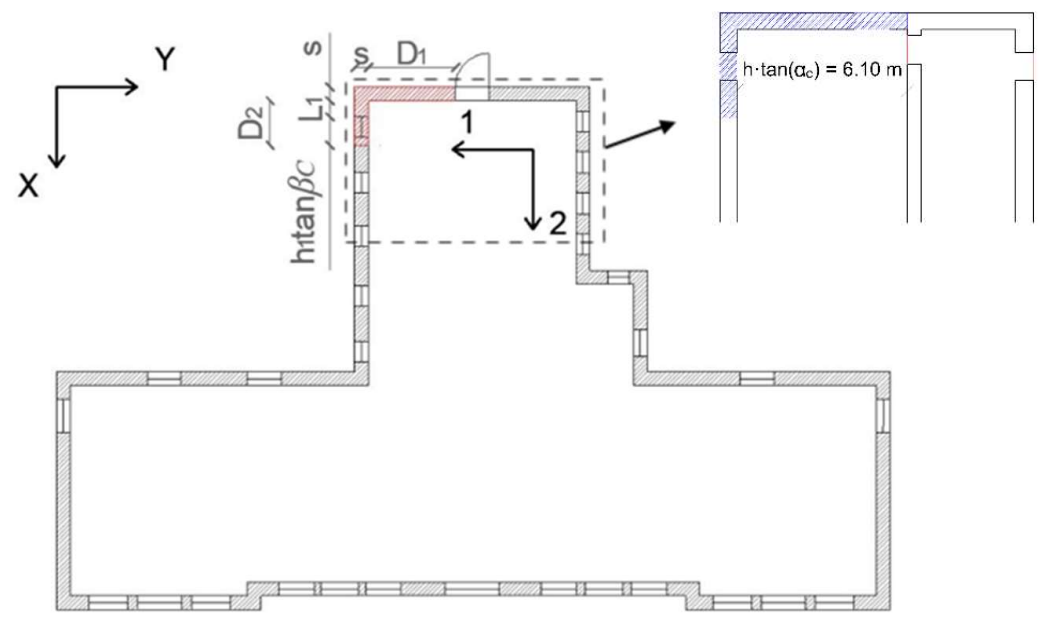

Figure 8: Plan of the building first floor and indication of the accelerometers direction.

The main characteristics of the considered earthquakes are shown in Table 2. It is possible to observe that the maximum Peak Floor Acceleration (PFA) is about $0.68 \mathrm{~g}$ and occurred on October $30^{\text {th }}$ in X direction, whereas the maximum PGV is about $100 \mathrm{~cm} / \mathrm{s}$, occurred on August $24^{\text {th }}$ in $\mathrm{Y}$ direction.

\begin{tabular}{|c|c|c|c|}
\cline { 2 - 4 } \multicolumn{1}{c|}{} & PFA [g] & PGA [g] & PGV [cm/s] \\
\hline August $24^{\text {th }}-\mathrm{X}$ & 0.61 & 0.32 & 55.95 \\
\hline August $24^{\text {th }}-\mathrm{Y}$ & 0.58 & 0.33 & 99.53 \\
\hline October $26^{\text {th }}-\mathrm{X}$ & 0.61 & 0.47 & 71.56 \\
\hline October $26^{\text {th }}-\mathrm{Y}$ & 0.44 & 0.36 & 70.34 \\
\hline October $30^{\text {th }}-\mathrm{X}$ & 0.68 & 0.30 & 46.14 \\
\hline October $30^{\text {th }}-\mathrm{Y}$ & 0.47 & 0.29 & 32.62 \\
\hline
\end{tabular}

Table 2: Main characteristics of the seismic records selected for the analysis (PGA Peak Ground Acceleration, PFA Peak Floor Acceleration, PGV Peak Ground Velocity).

\section{ANALYSIS AND RESULTS}

The local out-of-plane mode analyzed is the one side corner mechanism with 1) rotation around $\mathrm{X}$-axis (Figure 4);2) rotation around $\mathrm{Y}$-axis.

The corner mechanisms involve an incipient overturning of a masonry wing, which can be connected to the orthogonal wall at some extent, with the axis of rotation coinciding with one of the main building directions. Obviously, for the first model (rotation around X-axis), only accelerograms acting in Y-direction are considered and vice versa. This section illustrates the 
influence of geometry, energy dissipation and boundary conditions on the response and compares the numerical results with the real damages occurred to the case study.

\subsection{Parametric analysis of one-sided motion}

This paragraph describes the results of a parametric analysis considering geometry, energy dissipation levels and horizontal restraints.

\subsubsection{Influence of the geometry}

The influence of the geometry on the dynamic response of the corner mechanism in one-sided (1S) motion is here discussed. The geometric parameter chosen to vary the geometry is $\alpha_{c}$ (Figure 2), which is the one that mostly changes the mass and therefore the inertia moment of the masonry corner, while $\beta_{c}$ is fixed to $45^{\circ}$. This parametric analysis has the aim of evaluating, from a dynamic point of view, whether there is a critical geometry that amplifies the response in terms of normalized rotation.

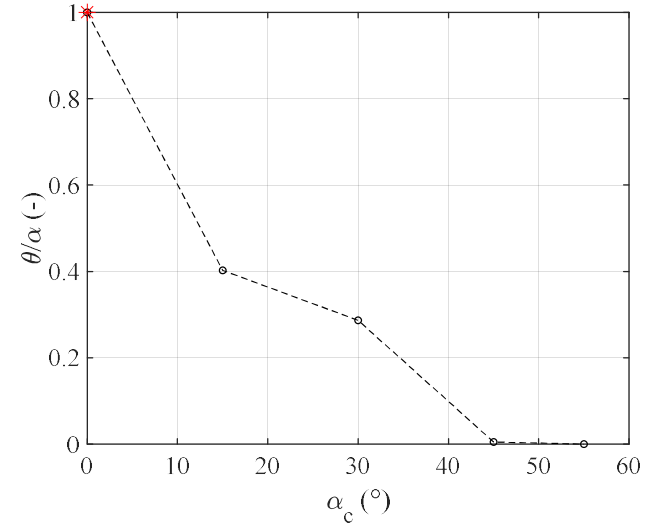

(a)

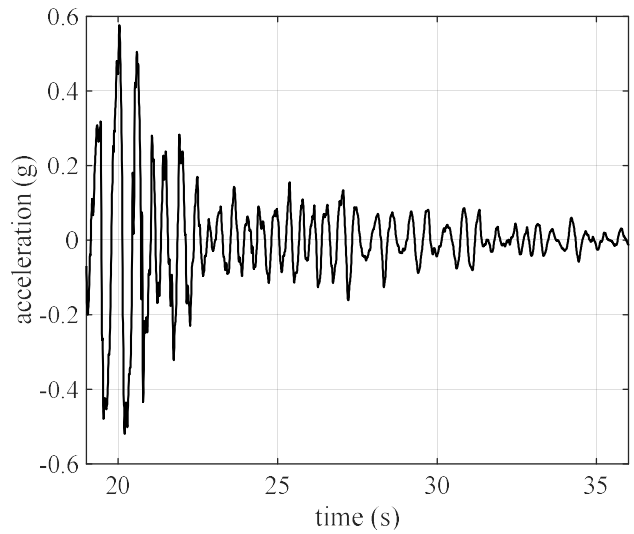

(c)

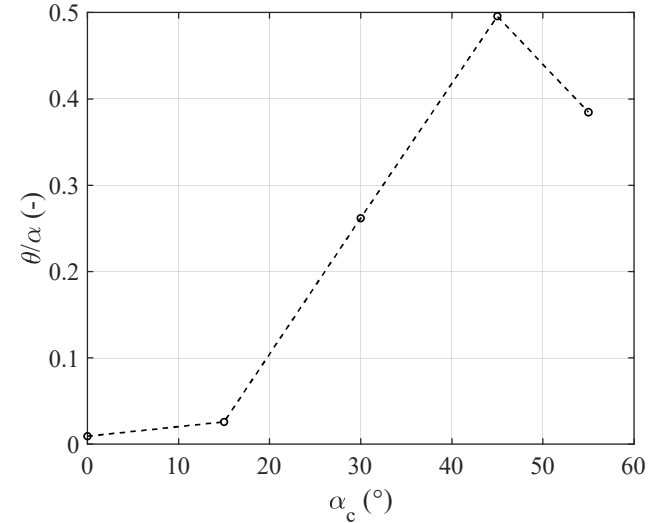

(b)

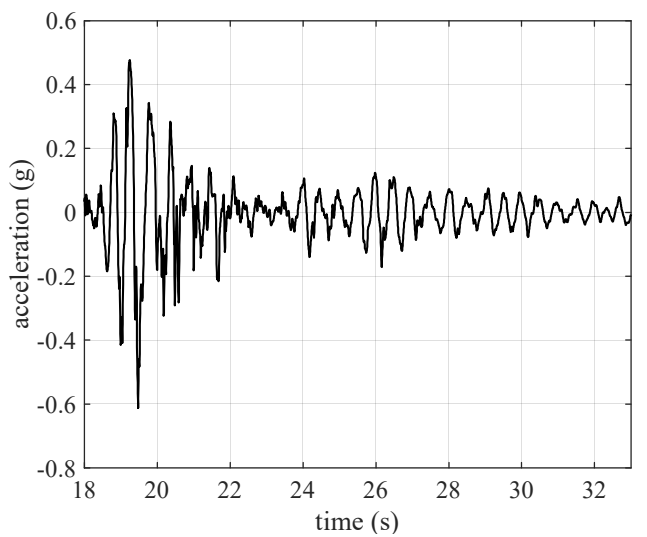

(d) 


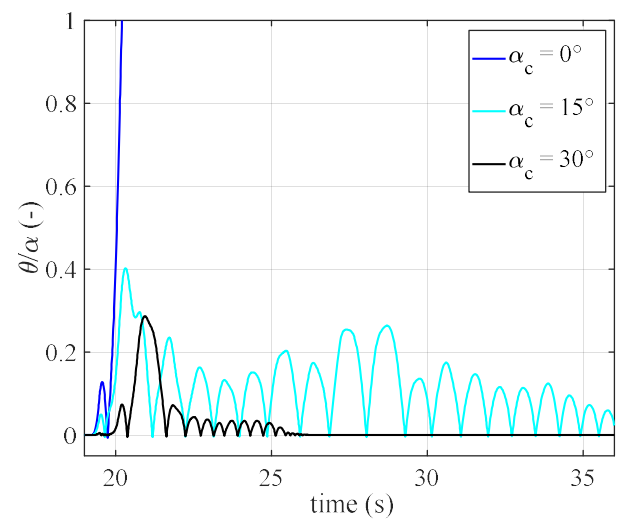

(e)

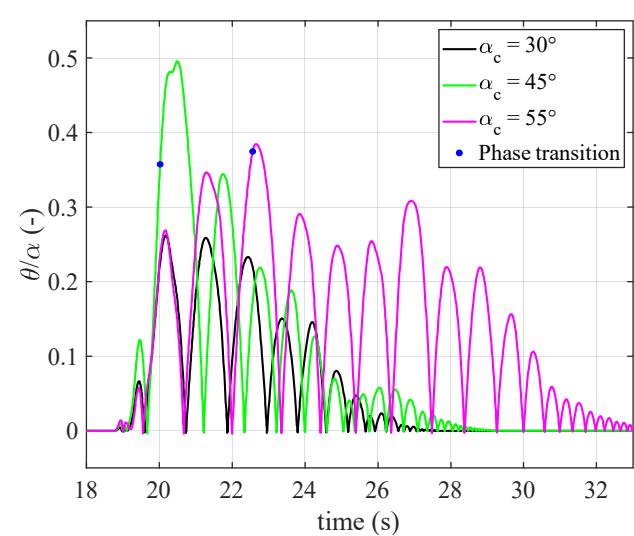

(f)

Figure 9: Influence of geometry change - August $24^{\text {th }}$ earthquake: (a), (c), (e) Y direction (Rotation around X); (b), (d), (f) X direction (Rotation around Y).

Five values of $\alpha_{c}$ are considered, from $0^{\circ}$ to $55^{\circ}$ (the latter considering the width of the wall up to the closest sidewall, namely 6.10 meters, Figure 8). The equation of motion (2) is time by time changed to take into account the variation of geometry. An angle equal to $\alpha_{c}=0^{\circ}$ corresponds to the rocking mechanism of the solely wall 2 rotating around $\mathrm{X}$ or $\mathrm{Y}$ axis. In these analyses the coefficient of restitution is kept equal to the analytical Housner's value [26]. In addition, the transverse walls stiffness is also kept constant (Table 1). For each earthquake, the results are reported in Figure 9-Figure 11. The results are displayed in terms of parametric curves showing the peaks of normalized rotation ( $\mathrm{a}, \mathrm{b}$ for $\mathrm{Y}$ and $\mathrm{X}$ direction respectively), the zoomed portions of the acceleration time-histories ( $\mathrm{c}, \mathrm{d}$, with values of acceleration greater than $0.01 \mathrm{PFA})$ and the corresponding responses of the corner mechanism (e,f), where blue circles mark the transition from phase 1 to phase 2 (§ 3.1). In Figure 9-Figure 11a,b, the stars indicate the overturning of the corner. A nominal value of $\frac{\vartheta}{\alpha}=1$ is chosen to identify this collapse condition, even though the rocking motion admits normalized rotations much higher than the static failure condition [27]. One can notice that the $1 \mathrm{~S}$ motion, in all the cases, exhibits the typical rebound effect due to the spring bed in compression (inward direction) that impedes the rotation to develop. A common trend for the three pairs of earthquakes in the two directions is visible: by increasing $\alpha_{c}$, the absolute values of rotation peaks decrease for the rotation around $\mathrm{X}$, whereas they increase for the rotation around Y. This is physically clear since the equivalent block thickness is respectively lower and greater, affecting the slenderness.

The maximum peaks are obtained for the August $24^{\text {th }}$ and October $26^{\text {th }}$ shocks with overturnings for $\alpha_{c}=0^{\circ}$ (rotation around X, August $24^{\text {th }}$ and October $\left.26^{\text {th }}\right)$ and for $\alpha_{c}=$ $30-55^{\circ}$ (rotation around Y, October $26^{\text {th }}$ ). Very small rotations are obtained for other geometries and are not shown in the corresponding time histories response Figures. When the equivalent block is stable, the maximum normalized rotation value is of about 0.6 , corresponding to a horizontal displacement of the center of mass in $\mathrm{X}$ direction of $40 \mathrm{~cm}$. At the top of the corner, this

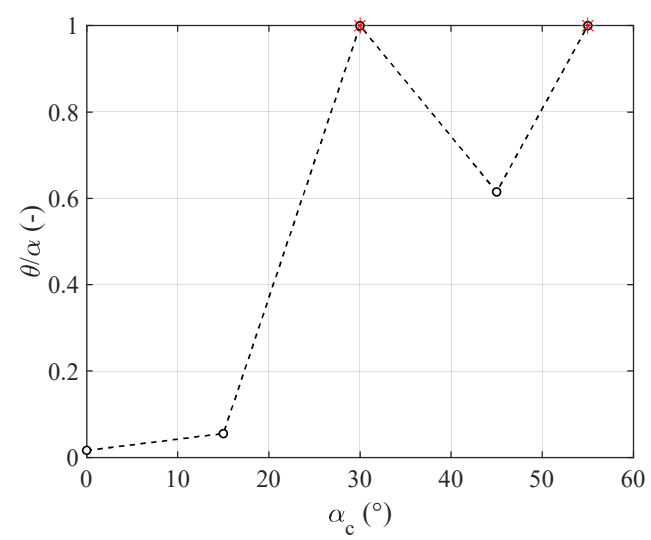

(b) 
value is about twice. Under October $30^{\text {th }}$ seismic shock, only the geometry $\alpha_{c}=55^{\circ}$ (rotation around $\mathrm{X}$ ) caused the phase transition at $t=18 \sec$ (Figure 11f).

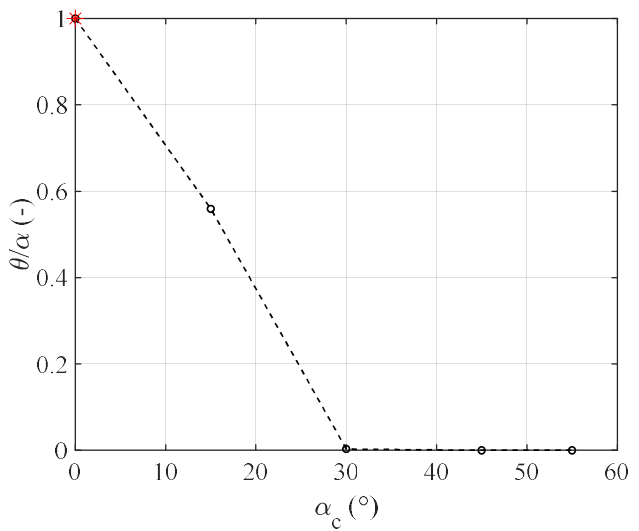

(a)
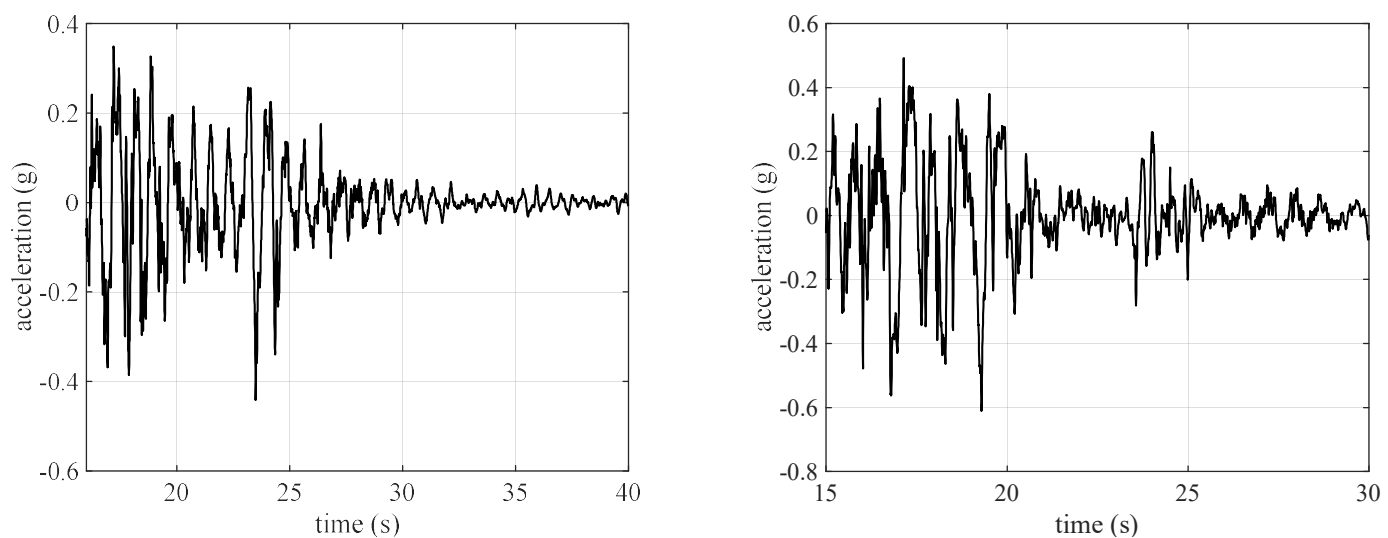

(c)

(d)

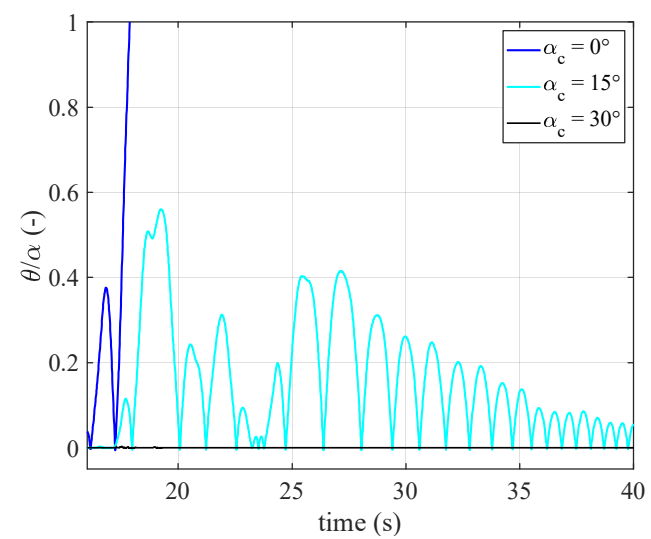

(e)

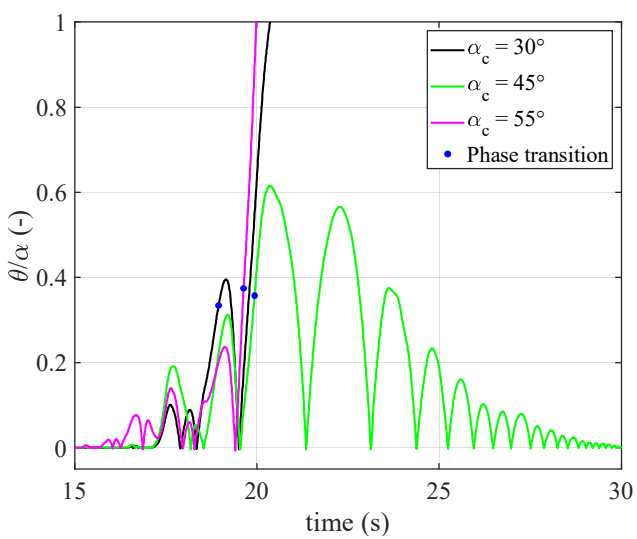

(f)

Figure 10: Influence of geometry change - October $26^{\text {th }}$ earthquake: (a), (c), (e) Y direction (Rotation around X); (b), (d), (f) $\mathrm{X}$ direction (Rotation around $\mathrm{Y}$ ). 


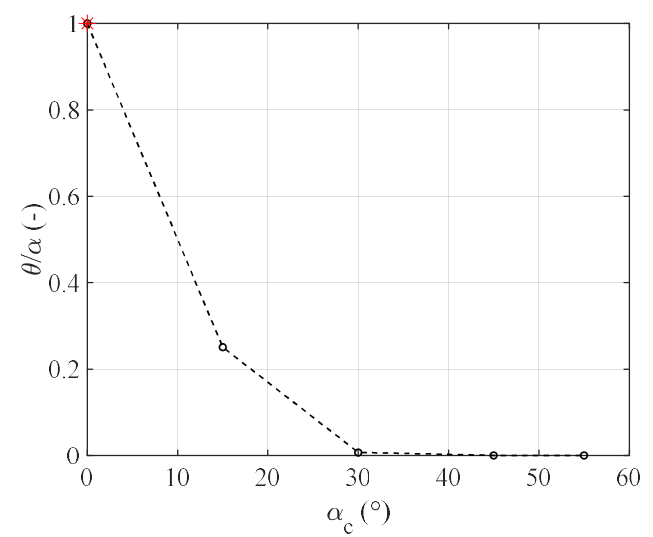

(a)

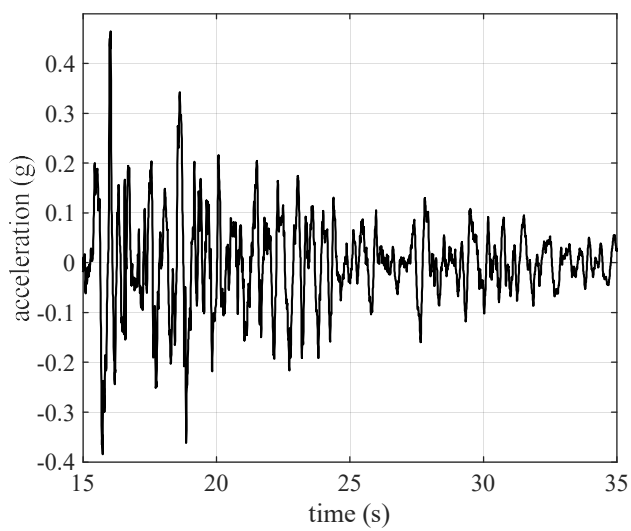

(c)

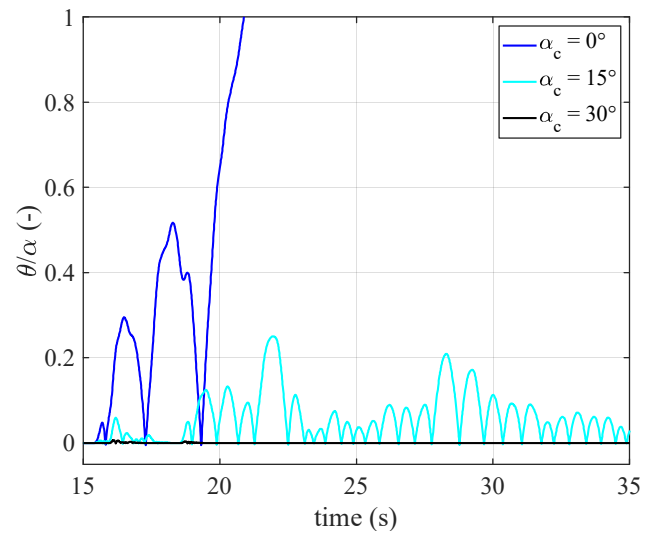

(e)

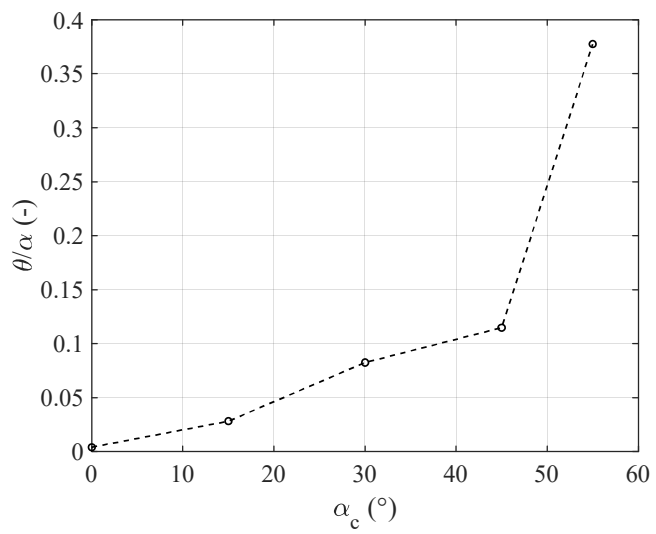

(b)

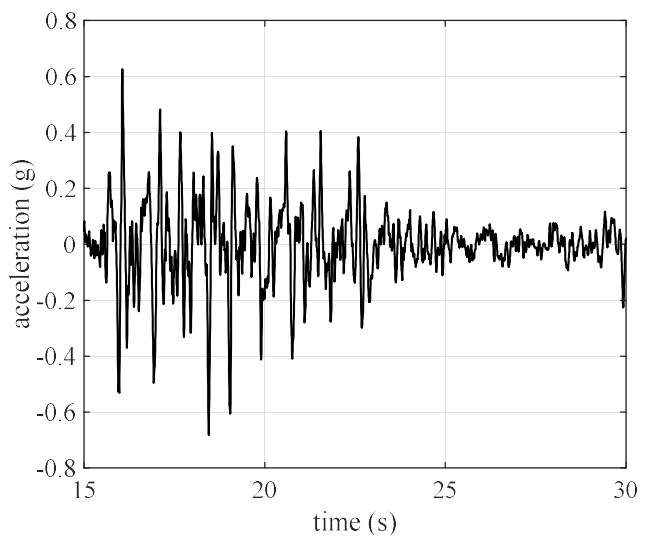

(d)

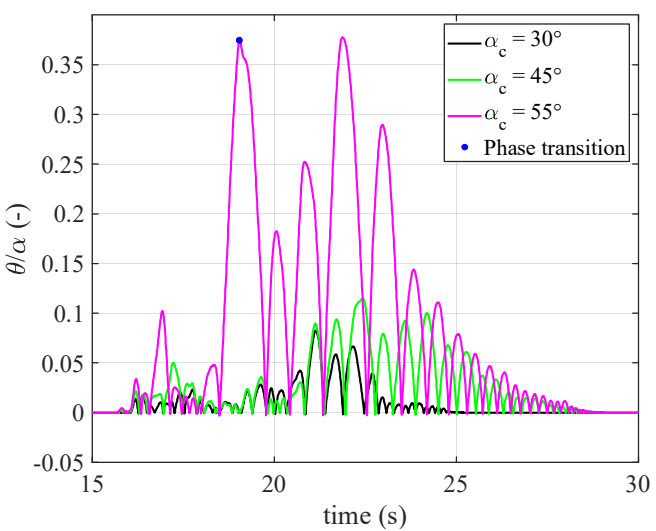

(f)

Figure 11: Influence of geometry change - October $30^{\text {th }}$ earthquake: (a), (c), (e) Y direction (Rotation around X); (b), (d), (f) X direction (Rotation around Y).

\subsubsection{Influence of the coefficient of restitution}

The influence of energy dissipation is evaluated through different values of coefficient of restitution for $\alpha_{c}=45^{\circ}$. The analytical value of coefficient of restitution changes when passing from phase 1 to phase 2 (as depending on $\alpha_{e q}$ ), but the greater values, namely those corresponding to phase 1, are considered: they are $e=0.94$ for rotation around Y model and $e=0.77$ for rotation around $\mathrm{X}$. Also, other values are set up to investigate how this parameter affects the 
response. The additional coefficients of restitution are for the rotation around Y $e=0.9$ and $e$ $=0.8$. Considering that experimental values of coefficient of restitution are between $85 \%$ [19] and $90 \%$ [20] the analytical Housner's value, these reference values are considered to be significant.

For the rotation around $\mathrm{X}$, it was considered $e=0.80$ and a greater value, $e=0.90$, typically adopted for more slender elements, are set: the response corresponding to this greater value is investigated to increase the response for a sake of safety, since it signifies a lower energy dissipation. Table 3 summarizes the values of coefficient of restitution chosen for the parametric analysis.

\begin{tabular}{|c|c|c|c|c|}
\hline Axis of rotation & $\alpha_{\mathrm{c}}$ & $\mathrm{e}_{\mathrm{H}}$ & $\mathrm{e}_{2}$ & $\mathrm{e}_{3}$ \\
\hline $\mathrm{X}-\mathrm{X}$ & $45^{\circ}$ & 0.77 & 0.80 & 0.90 \\
\hline $\mathrm{Y}-\mathrm{Y}$ & $45^{\circ}$ & 0.94 & 0.80 & 0.90 \\
\hline $\mathrm{X}-\mathrm{X}$ & $30^{\circ}$ & 0.90 & 0.675 & 0.80 \\
\hline
\end{tabular}

Table 3: Values of coefficient of restitution selected for the two models; $\mathrm{e}_{\mathrm{H}}$ is the Housner's analytical value

The time-history results from all earthquakes and rotation axes are shown in Figure 12, again zooming the peaks for making the reading clearer. It is evident that, when the rotation amplitudes are small, the influence of the coefficient of restitution is not relevant; by contrast, when the normalized rotations are over 0.1 , there is a significant variation of the response depending on the coefficient of restitution. In particular, the response shape is similar for the first rebounds, but after, when one considers e.g. the $85 \%$ of the analytical value $(0.8 / 0.94)$, the maximum peak is four times lower. Nevertheless, if the $95 \%$ of the analytical value is considered, the maximum peak is only about $20 \%$ of the original one (Figure $12 \mathrm{~b}$ ).

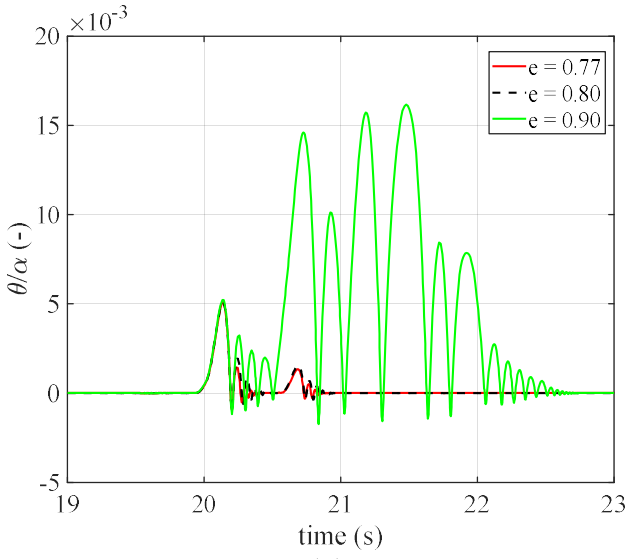

(a)

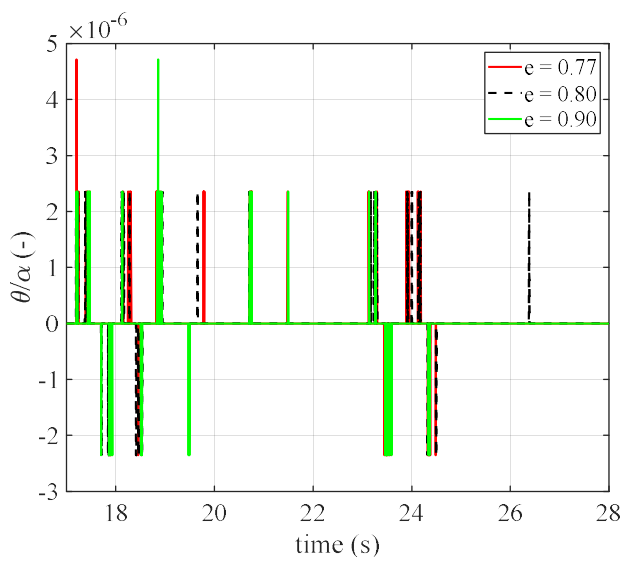

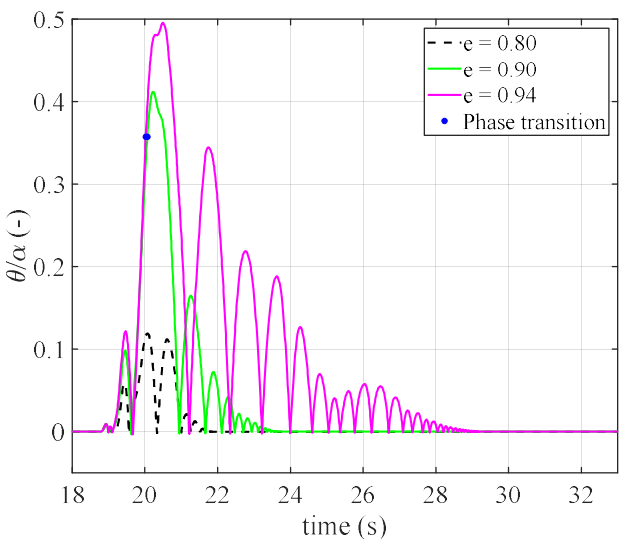

(b)

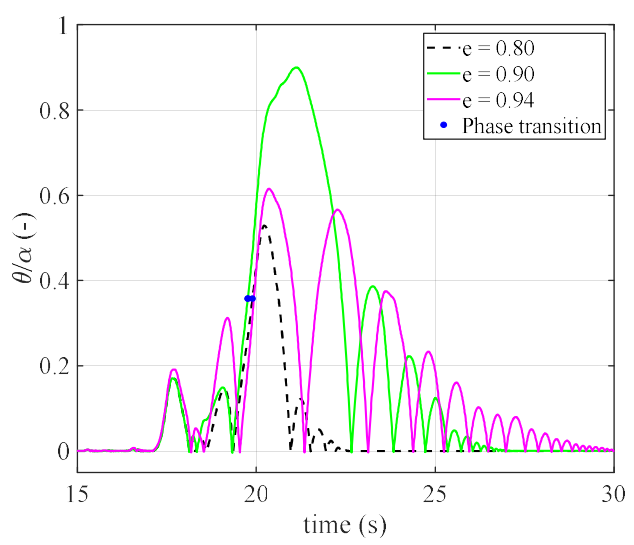


(c)

(d)

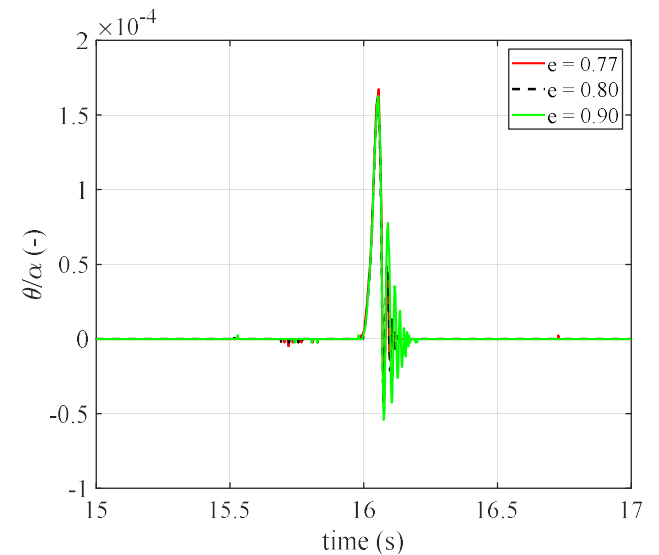

(e)

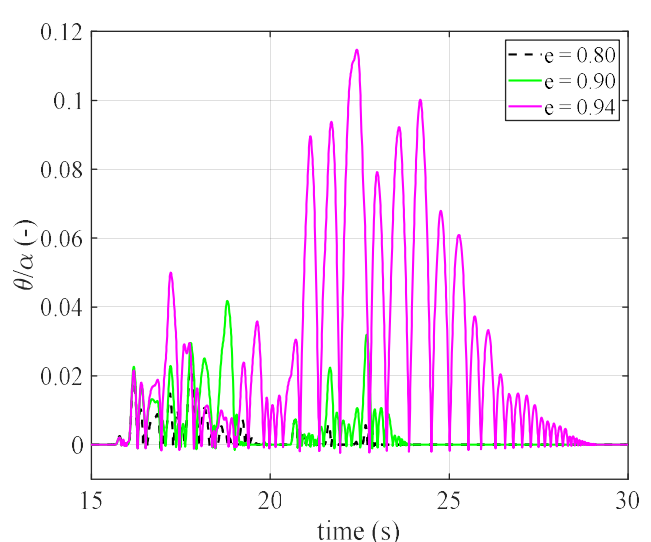

(f)

Figure 12: Influence of energy dissipation - August $24^{\text {th }}$ earthquake: rotation around X (a); August $24^{\text {th }}:$ rotation around Y (b); October $26^{\text {th }}$ earthquake: rotation around X (c); October $26^{\text {th }}$ : rotation around Y (d); October $30^{\text {th }}$ earthquake: rotation around $\mathrm{X}(\mathrm{e})$; October $30^{\text {th }}$ : rotation around $\mathrm{Y}(\mathrm{f})$.

Greater values of rotations around X-axis are obtained, e.g. for $\alpha_{c}=30^{\circ}$ (Figure 13). By adopting this change, the coefficient of restitution accordingly varies. In particular, the analytical coefficient of restitution becomes 0.9 ; this value is now assumed for the analysis with two extra values (0.675 and 0.80$)$ respectively corresponding to $75 \%$ and about $90 \%$ of the analytical value. Also in this case, the variation of the coefficient of restitution causes a modification of the response, although the general shape remains the same. In fact, as shown in (Figure 13a), the variation occurs for the second peak, for which the shape is the same but the maximum values increase by decreasing the amount of energy dissipation. Here, the maximum value is about 0.18 , corresponding to the minimum energy dissipation $(\mathrm{e}=0.90)$. One can notice that a $10 \%$ reduction of coefficient of restitution $(\mathrm{e}=0.80)$ couses a $30 \%$ reduction of the peak response. This fact underlines that there is no linear correlation between energy dissipation and peak values. Analogously to what discussed for the previous geometry $\left(\alpha_{c}=45^{\circ}\right)$, for small normalized rotations (order $10^{-3}$ ), the response sensitivity depending on the energy dissipation is not evident. 


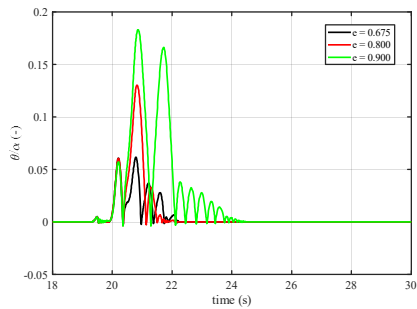

August $24^{\text {th }}-\mathrm{Y}$

(a)

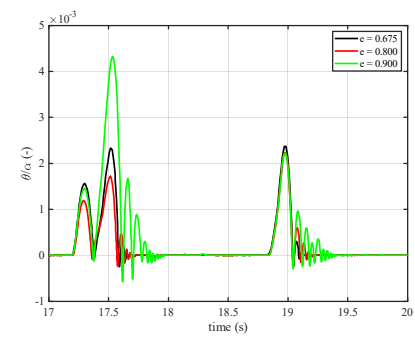

October $26^{\text {th }}-\mathrm{Y}$

(b)

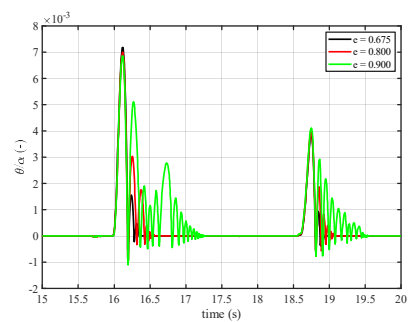

October $30^{\text {th }}-\mathrm{Y}$

(c)

Figure 13: Influence of energy dissipation - Model with rotation around X for $\alpha_{c}=30^{\circ}$.

\subsubsection{Influence of the sidewalls}

This paragraph discusses the results of the analysis performed by changing the compression spring bed stiffness values, considering an analytical value of coefficient of restitution $e=0.94$ for the rotation around $\mathrm{Y}$ axis and $e=0.77$ for the rotation around $\mathrm{X}$ axis. Taking into account that the real value of the spring bed stiffness is $1.57 \mathrm{E} 9 \mathrm{~N} / \mathrm{m} / \mathrm{m}$ for the rotation around $\mathrm{Y}$ axis and $5.49 \mathrm{E} 8 \mathrm{~N} / \mathrm{m} / \mathrm{m}$ for the rotation around $\mathrm{X}$ axis (Table 1), a second value of three order of magnitude greater has been considered, to investigate the case of a much stiffer adjacent wall. In addition, a third value three order of magnitude lower than the actual one is assumed. The one-sided motion is significantly affected by the value of the sidewalls when the oscillations are visible (normalized rotation values greater than 0.05 ), namely for the rotation around $\mathrm{Y}$ axis (Figure 14). Considering the August $24^{\text {th }}$ (rotation around Y), the different stiffness values hugely influence the response. In particular, for the more flexible adjacent wall, there are oscillations in the two directions instead of the rebound effect (slightly visible in the time-history), and the spring bed stiffness is not as high as that that it would be necessary to restrain the block. The minimum $K^{\prime}$ stiffness, calculated according to [10] (Eq. 45) to define a minimum value corresponding to a positive global system stiffness, is $12250.82 \mathrm{~N} / \mathrm{m} / \mathrm{m}$ for rotation around Y axis, while $12223.48 \mathrm{~N} / \mathrm{m} / \mathrm{m}$ for rotation around $\mathrm{X}$ axis. The August $24^{\text {th }}$ (rotation around $\mathrm{Y}$ ) is the only earthquake in $\mathrm{Y}$ direction that causes the block to oscillate; by contrast, the earthquakes in $\mathrm{X}$ direction give a clear rebound effect. Since for the actual stiffness value, the phase transition occurs at about 20 seconds (Figure 14b) but the peaks for the two stiffer cases do not change significantly. The peaks of the flexible adjacent wall are anyway lower in absolute value, and this happens also for the Oct. $26^{\text {th }}$ earthquake for which in case of stiffer walls there are two failure cases. The opposite occurs for the Oct. $30^{\text {th }}$ earthquake (Figure 14f), for which the response of the stiffer cases is less conservative. Thus, no specific trends are seen if the stiffness is reduced from the original value, but if one assumes a stiffness greater than the actual one, again the response shape is the same and the peaks are slightly higher.

The parametric analysis is shown in Figure 15, showing that for low values of $\alpha_{c}$ the influence of the sidewalls is relevant. When the rotations are small, the sidewalls nature does not affect the response. 

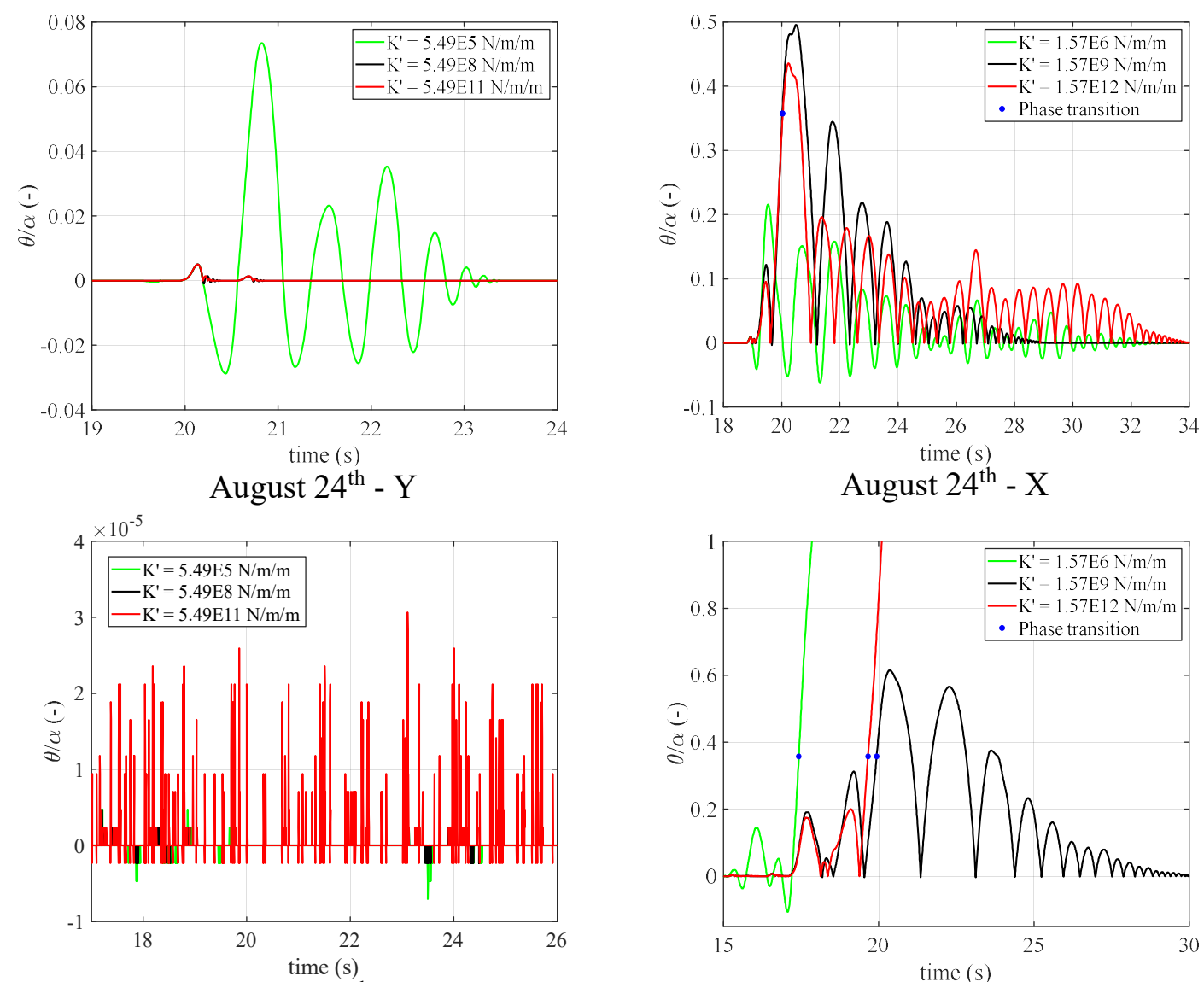

October $26^{\text {th }}-Y$

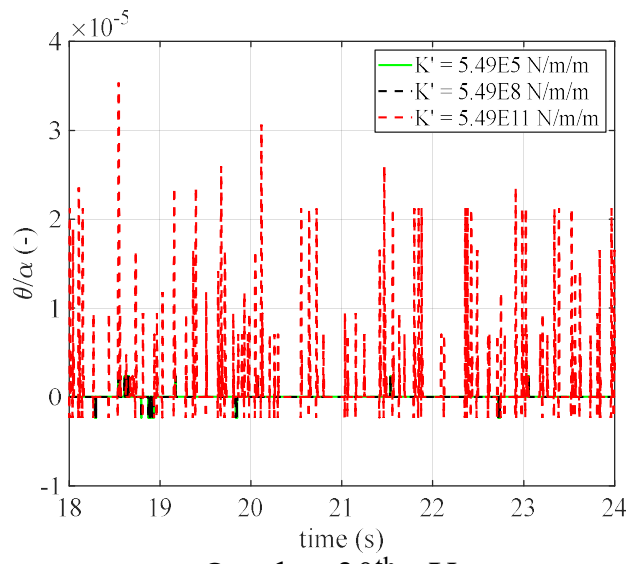

October $30^{\text {th }}-\mathrm{Y}$

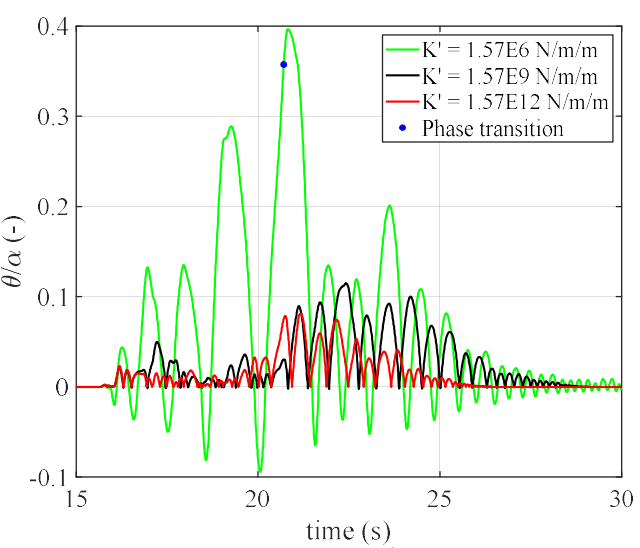

October $30^{\text {th }}-\mathrm{X}$

Figure 14: Influence of boundary condition for fixed geometry $\left(\alpha_{c}=45^{\circ}\right)$. 


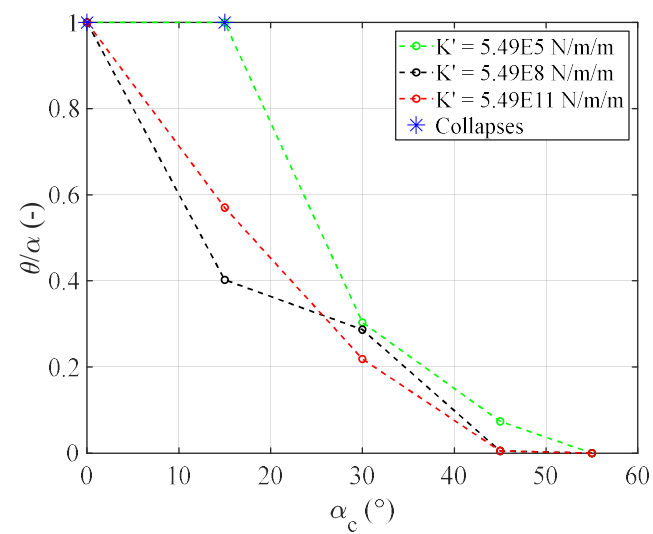

August $24^{\text {th }}-\mathrm{Y}$

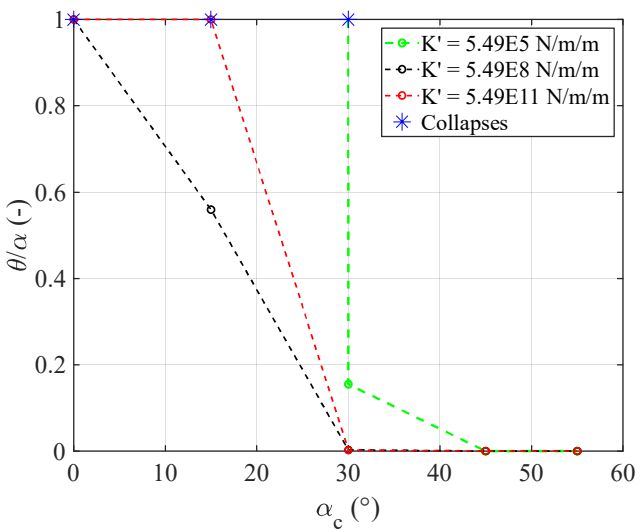

October $26^{\text {th }}-\mathrm{Y}$

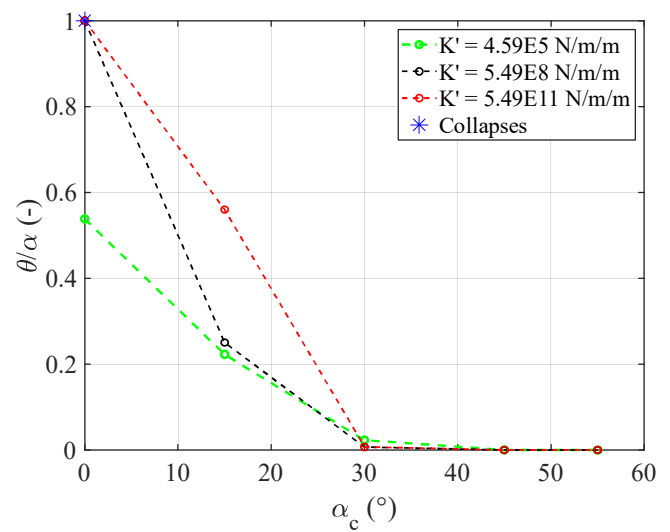

October $30^{\text {th }}-\mathrm{Y}$

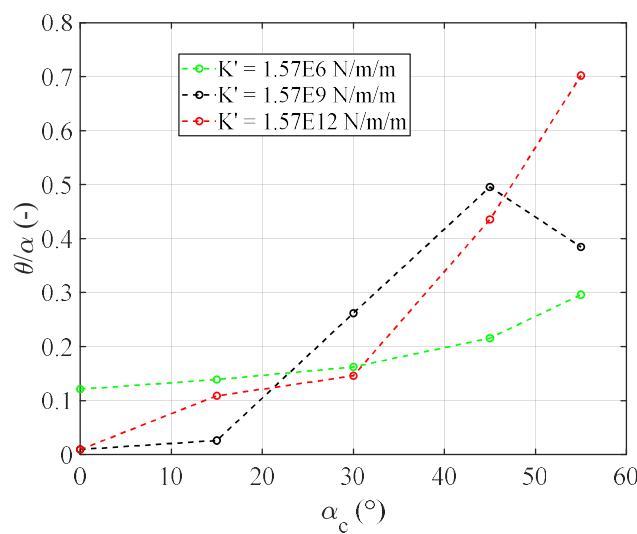

August $24^{\text {th }}-\mathrm{X}$

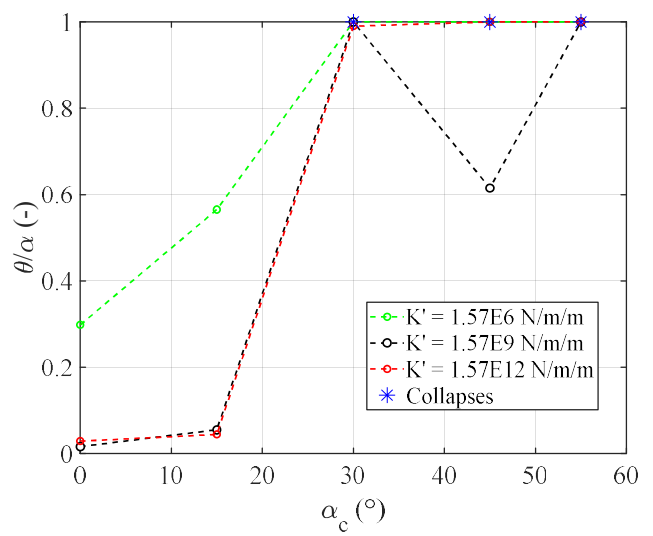

October $26^{\text {th }}-\mathrm{X}$

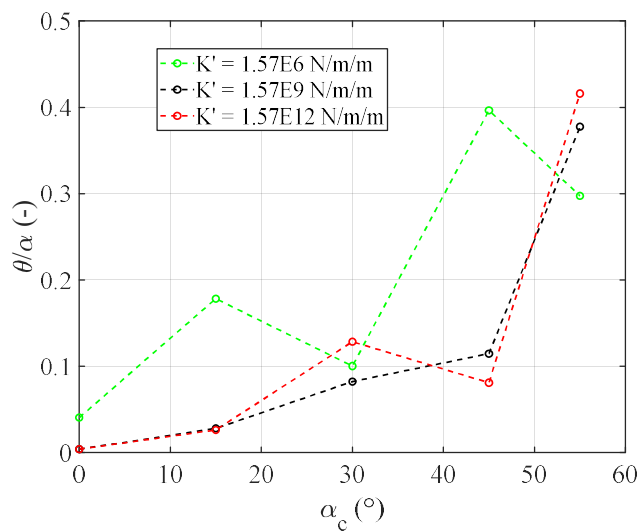

October $30^{\text {th }}-\mathrm{X}$

Figure 15: Influence of boundary condition for different geometries $\left(0^{\circ}<\alpha_{c}<55^{\circ}\right)$ for both directions.

\subsubsection{Comparison with the real damages and hypothesis of a retrofitting intervention}

The rocking non-linear dynamic analysis of the corner is here discussed and compared with what actually occurred to the masonry building during the 2016-2017 Central Italy earthquake. The numerical analysis shows that the earthquake that caused significant rotation was first the Aug. $24^{\text {th }}$, but it probably caused only the crack formation. Indeed, after this earthquake, no apparent damage was detected in the building. However, under the Oct. $26^{\text {th }}$ shock, the masonry 
corner actually collapsed, as visible in Figure $7 \mathrm{~b}$. This collapse is clearly detected by the rocking analyses, since high rotation values and overturning are obtained for $\boldsymbol{\alpha}_{c}=30-55^{\circ}$ (rotation around Y) and $\boldsymbol{\alpha}_{\boldsymbol{c}}=0^{\circ}$ (rotation around X). Obviously, the corner was not struck by the Oct. $30^{\text {th }}$ shock, since in that moment it was already collapsed. Nevertheless, the analyses show that a collapse could have occurred for $\boldsymbol{\alpha}_{c}=0^{\circ}$ (rotation around X). Since the actual collapse is associated to an angle of about $\boldsymbol{\alpha}_{\boldsymbol{c}}=50^{\circ}$, the rotation occurred around Y. As for the rotation around $\mathrm{X}$, this probably was avoided for a proper connection at the wall intersection, as it can be inferred from a correct disposal of corner blocks (Figure $7 \mathrm{~b}$, in the undamaged portion).

It is interesting to investigate what it could have occurred during the same earthquakes if the corner was restrained with steel tie rods. In particular, an analysis is performed under $30^{\text {th }}$ October seismic event in $\mathrm{X}$ direction, solving the equation of motion (2). The minimum value of tie stiffness for the global system stiffness $K_{\text {sys }}$ to be positive ([10] (Eq. 9)) is $2.9 \mathrm{E} 5 \mathrm{~N} / \mathrm{m}$. Therefore, a greater value of tie-rod stiffness should be chosen. The block is supposed to be restrained on top $(h=4.35 \mathrm{~m})$ by an ideal elastic steel tie with $20 \mathrm{~mm}$ diameter, $5 \mathrm{~m}$ length and a Young's modulus of 2.1E5 MPa. These assumptions give a steel tie rod of $1.32 \mathrm{E} 7 \mathrm{~N} / \mathrm{m}>>$ 2.9E5 N/m.

The clear beneficial effect of the device is shown in Figure 16a, reducing by one order of magnitude the maximum response peaks of the rotation without steel tie rods. The maximum horizontal elongation of the tie, corresponding to a normalized rotation of 0.01 , is $8.76 \mathrm{~mm}$. This value is greater than the yielding elongation of the tie, which is $6.5 \mathrm{~mm}$. Moreover, the influence of a $14 \mathrm{~mm}$ diameter tie but with same length as before is shown in Figure 16b. Its maximum horizontal displacement is $13.5 \mathrm{~mm}$, still significantly lower than the maximum without tie-rod of $65.4 \mathrm{~mm}$.

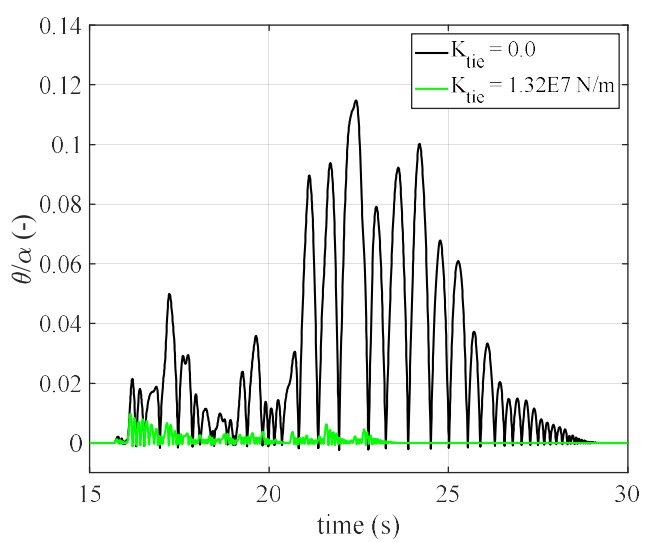

(a)

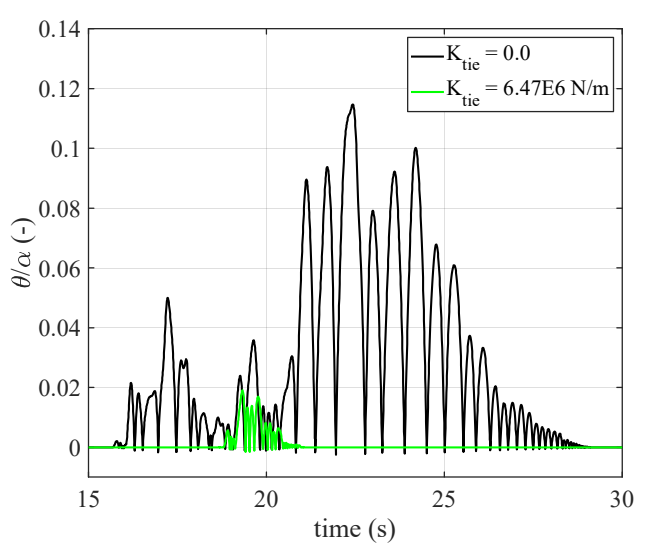

(b)

Figure 16: Influence of a steel tie rod for fixed geometry $\left(\alpha_{c}=45^{\circ}\right)$ and October $30^{\text {th }}$ earthquake in $\mathrm{X}$ direction.

\section{CONCLUSIONS}

This paper presented the extension of the classical Housner's equation of motion for the rocking analysis of rigid blocks to corner mechanisms, frequently observed in masonry structures subject to earthquakes. A one-sided (1S) motion is considered in the non-linear dynamic analyses, representing the two walls adjacent to the corner portion as spring bed of specific unitary stiffness. The methodology to obtain the equivalence between the $3 \mathrm{D}$ corner and the $2 \mathrm{D}$ rocking mechanism is illustrated and the equations of motion implemented in a specifically developed MATLAB code. 
The influence of geometry was investigated, referring to a real case of masonry building hit by the 2016 Central Italy earthquake, crossing the results with the those obtained from the variation of energy dissipation and boundary conditions (namely, the spring bed properties).

The response, for all the earthquakes, exhibits the typical rebound effect due to the spring bed only in compression (inward direction). A common trend for the three pairs of earthquakes is visible: by increasing the main geometrical parameter $\alpha_{c}$ (inclination of a diagonal crack bonding the corner mechanism), the absolute values of rotation peaks decrease (increase) for the rotation around $\mathrm{X}(\mathrm{Y})$ : this is physically justified from the adopted equivalence criterion. Even if five values of inclination angles are enough to get a general trend of the parametric curve, future works are intended to increase the data-set obtaining smoother curves.

The maximum peaks are obtained right for $\alpha_{c}=30-55^{\circ}$ (rotation around Y, Oct. $26^{\text {th }}$ ), attaining horizontal displacement of the center of mass of about $40 \mathrm{~cm}$ (in the condition near collapse) or exhibiting overturning. It is interesting to notice that this was the earthquake that actually caused the overturning of the masonry corner, and therefore the dynamic analysis appears to correctly predict this failure. A numerical test considering the beneficial effect of a steel tie-rod was made, assuming that the corner mechanism was restrained by a $20 \mathrm{~mm}$ tie-rod. In this case, a great improvement of the dynamic response was observed, with maximum rotation peaks about one order of magnitude lower. This could have possibly avoided the overturning of the corner.

It was shown that the influence of the coefficient of restitution, for the strongest earthquakes, can be relevant. In particular, when the normalized rotations are over 0.1 , there is a significant variation of the response depending on the coefficient of restitution. In general, for different geometries of the corner mechanism, the response shape is similar, but the peaks are different, not following a linear relationship between energy dissipation and response peaks.

The influence of the sidewalls stiffness is investigated with the actual value and two values three orders of magnitude greater and lower. The one-sided motion is significantly affected by the stiffness of the sidewalls if they are less rigid than the actual value (for stiffness not corresponding to physical values of masonry walls). For the more flexible adjacent walls, there are oscillations in the two directions instead of the rebound effect. One cannot say that the stiffer adjacent walls cause more conservative results if the stiffness is reduced from the original value, but if one assumes a stiffness greater than the actual one, again the response shape is the same and the peaks are slightly higher.

These aspects make it necessary to recommend, when a seismic vulnerability assessment of the stability of a corner is made, a parametric analysis varying the mechanical parameters involved in the rocking analysis. Such a parametric analysis should consider the variation of the coefficient of restitution, of the stiffness of the sidewalls and especially of the geometry. The latter can be considered by varying the inclination angle of the diagonal crack, identifying the most dangerous configuration as that that produces the greatest values of rotation amplitude. If necessary, the response can be improved by the installation of a tie-rod to de-amplify the maximum response.

\section{ACKNOWLEDGEMENTS}

The Authors thank the Italian Department of Civil Protection and the Consortium RELUIS (2018) for funding this research activity. This work was partially financed by FEDER funds through the Competitiveness Factors Operational Program - COMPETE and by national funds 
through FCT - Foundation for Science and Technology within the scope of the project POCI01-0145-FEDER-007633.

\section{APPENDIX A}

Referring to Figure 2, the coordinates of the center of mass of the model adopted in Phase 1 is:

$$
\begin{aligned}
& X_{G 1}=\left(\begin{array}{l}
\rho \cdot \mathrm{h}_{1}{ }^{2} \cdot \tan \left(\beta_{C}\right) / 2 \cdot \mathrm{sp} \cdot\left(\mathrm{L}_{1}+\mathrm{sp}+\mathrm{h}_{1} \cdot\left[\tan \left(\beta_{C}\right)\right] / 3\right)+ \\
+\rho \cdot \mathrm{L}_{1} \cdot \mathrm{sp} \cdot\left(\mathrm{h}_{1}+\mathrm{h}_{2}\right) \cdot\left(\mathrm{sp}+\mathrm{L}_{1} / 2\right)+\rho \cdot \mathrm{L}_{1} \cdot \mathrm{sp} \cdot \mathrm{h}_{3} / 2 \cdot\left(\mathrm{sp}+\mathrm{L}_{1} / 3\right)+ \\
+\rho \cdot \mathrm{sp}^{2} \cdot \mathrm{h} \cdot(\mathrm{sp} / 2)+\rho \cdot \mathrm{h}^{2} \cdot \tan \left(\alpha_{C}\right) / 2 \cdot \mathrm{sp} \cdot(\mathrm{sp} / 2)+ \\
+\mathrm{m}_{B} \cdot \mathrm{sp} / 2+\mathrm{m}_{C} \cdot\left(\mathrm{sp}+D_{2} / 2\right)+\mathrm{m}_{A} \cdot \mathrm{sp} / 2
\end{array}\right) /\left(\begin{array}{l}
\rho \cdot \mathrm{h}_{1}{ }^{2} \cdot \tan \left(\beta_{C}\right) / 2 \cdot \mathrm{sp}+\rho \cdot \mathrm{L}_{1} \cdot \mathrm{sp} \cdot\left(\mathrm{h}_{1}+\mathrm{h}_{2}\right)+ \\
+\rho \cdot \mathrm{L}_{1} \cdot \mathrm{sp} \cdot \mathrm{h}_{3} / 2+\rho \cdot \mathrm{sp}^{2} \cdot \mathrm{h}+ \\
+\rho \cdot \mathrm{h}^{2} \cdot \tan \left(\alpha_{C}\right) / 2 \cdot \mathrm{sp}+\mathrm{m}_{B}+\mathrm{m}_{C}+\mathrm{m}_{A}
\end{array}\right) \\
& Y_{G 1}=\left(\begin{array}{l}
\rho \cdot \mathrm{h}_{1}^{2} \cdot \tan \left(\beta_{C}\right) / 2 \cdot \mathrm{sp}^{2} / 2+ \\
+\rho \cdot \mathrm{L}_{1} \cdot \mathrm{sp} \cdot\left(\mathrm{h}_{1}+\mathrm{h}_{2}\right) \cdot(\mathrm{sp} / 2)+\rho \cdot \mathrm{L}_{1} \cdot \mathrm{sp} \cdot \mathrm{h}_{3} / 2 \cdot(\mathrm{sp} / 2)+ \\
+\rho \cdot \mathrm{sp}^{2} \cdot \mathrm{h} \cdot(\mathrm{sp} / 2)+\rho \cdot \mathrm{h}^{2} \cdot \tan \left(\alpha_{C}\right) / 2 \cdot \mathrm{sp} \cdot\left[\mathrm{sp}+\mathrm{h} \cdot \tan \left(\alpha_{C}\right) / 3\right] \\
+\mathrm{m}_{B} \cdot\left(\mathrm{sp}+\mathrm{D}_{1} / 2\right)+\mathrm{m}_{C} \cdot \mathrm{sp} / 2+\mathrm{m}_{A} \cdot \mathrm{sp} / 2
\end{array}\right) /\left(\begin{array}{l}
\rho \cdot \mathrm{h}_{1}{ }^{2} \cdot \tan \left(\beta_{C}\right) / 2 \cdot \mathrm{sp}+\rho \cdot \mathrm{L}_{1} \cdot \mathrm{sp} \cdot\left(\mathrm{h}_{1}+\mathrm{h}_{2}\right)+ \\
+\rho \cdot \mathrm{L}_{1} \cdot \mathrm{sp} \cdot \mathrm{h}_{3} / 2+\rho \cdot \mathrm{sp}^{2} \cdot \mathrm{h}+ \\
+\rho \cdot \mathrm{h}^{2} \cdot \tan \left(\alpha_{C}\right) / 2 \cdot \mathrm{sp}+\mathrm{m}_{B}+\mathrm{m}_{C}+\mathrm{m}_{A}
\end{array}\right) \\
& \mathrm{Z}_{\mathrm{G} 1}=\left(\begin{array}{l}
\rho \cdot \mathrm{h}_{1}{ }^{2} \cdot \tan \left(\beta_{\mathrm{C}}\right) / 2 \cdot \mathrm{sp} \cdot\left(2 \cdot \mathrm{h}_{1} / 3+\mathrm{h}_{2}+\mathrm{h}_{3}\right)+ \\
+\rho \cdot \mathrm{L}_{1} \cdot \mathrm{sp} \cdot\left(\mathrm{h}_{1}+\mathrm{h}_{2}\right) \cdot\left[\left(\mathrm{h}_{1}+\mathrm{h}_{2}\right) / 2+\mathrm{h}_{3}\right]+\rho \cdot \mathrm{L}_{1} \cdot \mathrm{sp} \cdot \mathrm{h}_{3} / 2 \cdot\left(2 \cdot \mathrm{h}_{3} / 3\right)+ \\
+\rho \cdot \mathrm{sp}^{2} \cdot \mathrm{h} \cdot \mathrm{h} / 2+\rho \cdot \mathrm{h}^{2} \cdot \tan \left(\alpha_{C}\right) / 2 \cdot \mathrm{sp} \cdot 2 \cdot \mathrm{h} / 3+ \\
+\mathrm{m}_{B} \cdot\left(\mathrm{sp}+\mathrm{D}_{1} / 2\right)+\mathrm{m}_{C} \cdot \mathrm{sp} / 2+\mathrm{m}_{A} \cdot \mathrm{sp} / 2
\end{array}\right) \quad\left(\begin{array}{l}
\rho \cdot \mathrm{h}_{1}{ }^{2} \cdot \tan \left(\beta_{c}\right) / 2 \cdot \mathrm{sp}+\rho \cdot \mathrm{L}_{1} \cdot \mathrm{sp} \cdot\left(\mathrm{h}_{1}+\mathrm{h}_{2}\right)+ \\
+\rho \cdot \mathrm{L}_{1} \cdot \mathrm{sp} \cdot \mathrm{h}_{3} / 2+\rho \cdot \mathrm{sp}^{2} \cdot \mathrm{h}+ \\
+\rho \cdot \mathrm{h}^{2} \cdot \tan \left(\alpha_{C}\right) / 2 \cdot \mathrm{sp}+\mathrm{m}_{B}+\mathrm{m}_{C}+\mathrm{m}_{A}
\end{array}\right)
\end{aligned}
$$

whereas for Phase 2 one has:

$$
\begin{aligned}
& X_{G 0}=\left(\begin{array}{l}
\rho \cdot \mathrm{h}_{1}{ }^{2} \cdot \tan \left(\beta_{C}\right) / 2 \cdot \mathrm{sp} \cdot\left[\mathrm{L}_{1}+\mathrm{L}_{2}+\mathrm{h}_{1} \cdot \tan \left(\beta_{C}\right) / 3\right]+ \\
+\rho \cdot \mathrm{L}_{1} \cdot \mathrm{sp} \cdot\left(\mathrm{h}_{1}+\mathrm{h}_{2}\right) \cdot\left(\mathrm{sp}+\mathrm{L}_{1} / 2\right)+\rho \cdot \mathrm{L}_{1} \cdot \mathrm{sp} \cdot \mathrm{h}_{3} / 2 \cdot\left(\mathrm{sp}+\mathrm{L}_{1} / 3\right)+ \\
+\rho \cdot \mathrm{sp}^{2} \cdot \mathrm{h} \cdot(\mathrm{sp} / 2)+\rho \cdot \mathrm{h}^{2} \cdot \tan \left(\alpha_{C}\right) / 2 \cdot \mathrm{sp} \cdot(\mathrm{sp} / 2)
\end{array}\right) /\left(\begin{array}{l}
\rho \cdot \mathrm{h}_{1}{ }^{2} \cdot \tan \left(\beta_{C}\right) / 2 \cdot \mathrm{sp}+\rho \cdot \mathrm{L}_{1} \cdot \mathrm{sp} \cdot\left(\mathrm{h}_{1}+\mathrm{h}_{2}\right)+ \\
+\rho \cdot \mathrm{L}_{1} \cdot \mathrm{sp} \cdot \mathrm{h}_{3} / 2+\rho \cdot \mathrm{sp}^{2} \cdot \mathrm{h}+ \\
+\rho \cdot \mathrm{h}^{2} \cdot \tan \left(\alpha_{C}\right) / 2 \cdot \mathrm{sp}
\end{array}\right) \\
& Y_{G 0}=\left(\begin{array}{l}
\rho \cdot \mathrm{h}_{1}^{2} \cdot \tan \left(\beta_{C}\right) / 2 \cdot \mathrm{sp}^{2} / 2+ \\
+\rho \cdot \mathrm{L}_{1} \cdot \mathrm{sp} \cdot\left(\mathrm{h}_{1}+\mathrm{h}_{2}\right) \cdot(\mathrm{sp} / 2)+\rho \cdot \mathrm{L}_{1} \cdot \mathrm{sp} \cdot \mathrm{h}_{3} / 2 \cdot(\mathrm{sp} / 2)+ \\
+\rho \cdot \mathrm{sp} \mathrm{p}^{2} \cdot \mathrm{h} \cdot(\mathrm{sp} / 2)+\rho \cdot \mathrm{h}^{2} \cdot \tan \left(\alpha_{C}\right) / 2 \cdot \mathrm{sp} \cdot\left[\mathrm{sp}+\mathrm{h} \cdot \tan \left(\alpha_{C}\right) / 3\right.
\end{array}\right) /\left(\begin{array}{l}
\rho \cdot \mathrm{h}_{1}{ }^{2} \cdot \tan \left(\beta_{C}\right) / 2 \cdot \mathrm{sp}+\rho \cdot \mathrm{L}_{1} \cdot \mathrm{sp} \cdot\left(\mathrm{h}_{1}+\mathrm{h}_{2}\right)+ \\
+\rho \cdot \mathrm{L}_{1} \cdot \mathrm{sp} \cdot \mathrm{h}_{3} / 2+\rho \cdot \mathrm{sp} \cdot \mathrm{h}+ \\
+\rho \cdot \mathrm{h}^{2} \cdot \tan \left(\alpha_{C}\right) / 2 \cdot \mathrm{sp}
\end{array}\right) \\
& Z_{G 0}=\left(\begin{array}{l}
\rho \cdot \mathrm{h}_{1}^{2} \cdot \tan \left(\beta_{C}\right) / 2 \cdot \mathrm{sp} \cdot\left(2 \cdot \mathrm{h}_{1} / 3+\mathrm{h}_{2}+\mathrm{h}_{3}\right)+ \\
+\rho \cdot \mathrm{L}_{1} \cdot \mathrm{sp} \cdot\left(\mathrm{h}_{1}+\mathrm{h}_{2}\right) \cdot\left[\left(\mathrm{h}_{1}+\mathrm{h}_{2}\right) / 2+\mathrm{h}_{3}\right]+\rho \cdot \mathrm{L}_{1} \cdot \mathrm{sp} \cdot \mathrm{h}_{3} / 2 \cdot\left(2 \cdot \mathrm{h}_{3} / 3\right)+ \\
+\rho \cdot \mathrm{sp}^{2} \cdot \mathrm{h}^{2} / 2+\rho \cdot \mathrm{h}^{2} \cdot \tan \left(\alpha_{C}\right) / 2 \cdot \mathrm{sp} \cdot(2 \cdot \mathrm{h} / 3)
\end{array}\right) /\left(\begin{array}{l}
\rho \cdot \mathrm{h}_{1}^{2} \cdot \tan \left(\beta_{C}\right) / 2 \cdot \mathrm{L}_{3}+\rho \cdot \mathrm{L}_{1} \cdot \mathrm{sp} \cdot\left(\mathrm{h}_{1}+\mathrm{h}_{2}\right)+ \\
+\rho \cdot \mathrm{L}_{1} \cdot \mathrm{sp} \cdot \mathrm{h}_{3} / 2+\rho \cdot s p^{2} \cdot \mathrm{h}+ \\
+\rho \cdot \mathrm{h}^{2} \cdot \tan \left(\alpha_{C}\right) / 2 \cdot \mathrm{sp}
\end{array}\right)
\end{aligned}
$$

The inertia moments $\boldsymbol{I}_{\boldsymbol{X} \mathbf{0}}$ and $\boldsymbol{I}_{\boldsymbol{Y} \mathbf{0}}$ (respectively with respect to $\mathrm{X}$ and $\mathrm{Y}$ axes) of the corner mechanism for Phase 2 are:

$$
\begin{aligned}
& I_{X, 0}=\rho \cdot \mathrm{h}_{1}{ }^{2} \cdot \tan \left(\beta_{C}\right) / 2 \cdot L_{3} \cdot\left[\left(h_{1}{ }^{2}+L_{3}{ }^{2}\right) / 18+\left(2 \cdot h_{1} / 3+h_{2}+h_{3}\right)^{2}+\left(L_{3} / 2\right)^{2}\right]+ \\
& +\rho \cdot \mathrm{L}_{1} \cdot \mathrm{L}_{3} \cdot\left(\mathrm{h}_{1}+\mathrm{h}_{2}\right) \cdot\left[\left(L_{1}^{2}+\left(h_{1}+h_{2}\right)^{2}\right] / 12+\left(L_{3} / 2\right)^{2}+\left[\left(h_{1}+h_{2}\right) / 2+h_{3}\right)^{2}\right]+ \\
& +\rho \cdot \mathrm{L}_{1} \cdot \mathrm{L}_{3} \cdot \mathrm{h}_{3} / 2 \cdot\left(\left(h_{3}{ }^{2}+L_{3}{ }^{2}\right) / 18+\left(2 \cdot h_{3} / 3\right)^{2}+\left(L_{3} / 2\right)^{2}\right)+ \\
& +\rho \cdot \mathrm{L}_{2} \cdot \mathrm{L}_{3} \cdot \mathrm{h} \cdot\left(\left(h^{2}+L_{2}{ }^{2}\right) / 12+(h / 2)^{2}+\left(L_{3} / 2\right)^{2}\right)+ \\
& +\rho \cdot \mathrm{h}^{2} \cdot \tan \left(\alpha_{C}\right) / 2 \cdot \mathrm{L}_{2} \cdot\left\{\left\{\left[h \cdot \tan \left(\alpha_{C}\right)\right]^{2}+h^{2}\right\} / 18+(2 \cdot h / 3)^{2}+\left(h \cdot \tan \left(\alpha_{C}\right) / 3+L_{3}\right)^{2}\right\}
\end{aligned}
$$




$$
\begin{aligned}
& I_{Y, 0}=\rho \cdot \mathrm{h}_{1}^{2} \cdot \frac{\tan \left(\beta_{\mathrm{c}}\right)}{2} \cdot \mathrm{L}_{3} \cdot\left[\frac{h_{1}^{2}+\left(h_{1} \cdot \tan \left(\beta_{\mathrm{c}}\right)^{2}\right.}{18}+\left(\mathrm{L}_{1}+L_{2}+\frac{h_{1} \cdot \tan \left(\beta_{\mathrm{c}}\right)}{3}\right)^{2}+\left(\frac{2 \cdot h_{1}}{3}+h_{2}+h_{3}\right)^{2}\right]+ \\
& +\rho \cdot \mathrm{L}_{1} \cdot \mathrm{L}_{3} \cdot\left(\mathrm{h}_{1}+\mathrm{h}_{2}\right) \cdot\left\{\left(L_{3}^{2}+\left(h_{1}+h_{2}\right)^{2}\right) / 12+\left(L_{1} / 2+L_{2}\right)^{2}+\left[\left(h_{1}+h_{2}\right) / 2+h_{3}\right]^{2}\right\}+ \\
& +\rho \cdot \mathrm{L}_{1} \cdot \mathrm{L}_{3} \cdot \mathrm{h}_{3} / 2 \cdot\left[\left(L_{1}^{2}+h_{3}^{2}\right) / 18+\left(2 \cdot h_{3} / 3\right)^{2}+\left(L_{1} / 3+L_{2}\right)^{2}\right]+ \\
& +\rho \cdot \mathrm{L}_{2} \cdot \mathrm{L}_{3} \cdot \mathrm{h} \cdot\left[\left(h^{2}+L_{3}^{2}\right) / 12+(h / 2)^{2}+\left(L_{2} / 2\right)^{2}\right]+ \\
& +\rho \cdot \mathrm{h}^{2} \cdot \tan \left(\alpha_{\mathrm{c}}\right) / 2 \cdot \mathrm{L}_{2} \cdot\left\{\left[\left(h^{2}+L_{2}^{2}\right) / 18\right]+(h \cdot 2 / 3)^{2}+\left(L_{2} / 2\right)^{2}\right\} \\
& I_{X Y, 0}=\rho \cdot \mathrm{h}_{1}{ }^{2} \cdot \tan \left(\beta_{C}\right) / 2 \cdot L_{3} \cdot\left(\mathrm{L}_{2}+\mathrm{L}_{1}+\mathrm{h}_{1} \cdot \tan \left(\beta_{C}\right) / 3\right)+ \\
& +\rho \cdot \mathrm{L}_{1} \cdot \mathrm{L}_{3} \cdot\left(h_{1}+\mathrm{h}_{2}\right) \cdot \mathrm{h}_{3} / 2 \cdot \mathrm{L}_{3} / 2 \cdot\left(\mathrm{L}_{2}+\mathrm{L}_{1} / 2\right)+ \\
& +\rho \cdot \mathrm{L}_{1} \cdot \mathrm{L}_{3} \cdot\left(\mathrm{h}_{3} / 2\right) \cdot\left(\mathrm{L}_{2}+\mathrm{L}_{1} / 3\right) \cdot \mathrm{L}_{3} / 2+ \\
& +\rho \cdot \mathrm{L}_{2} \cdot \mathrm{L}_{3} \cdot \mathrm{h} \cdot \mathrm{L}_{2} / 2 \cdot \mathrm{L}_{3} / 2+ \\
& +\rho \cdot \mathrm{h}^{2} \cdot \tan \left(\alpha_{C}\right) / 2 \cdot \mathrm{L}_{2} \cdot\left(\mathrm{L}_{2}+\mathrm{h} \cdot \tan \left(\alpha_{C}\right) / 3\right) \cdot \mathrm{L}_{2} / 2
\end{aligned}
$$

whereas for Phase 1 one has the contribution of the roof masses on the points A, B and C (Figure 2 ), therefore the corresponding inertia moments $\boldsymbol{I}_{\boldsymbol{X} \mathbf{1}}$ and $\boldsymbol{I}_{\boldsymbol{Y} \mathbf{1}}$ are:

$$
\begin{aligned}
& I_{X, 1}=I_{X, 2}+m_{A} \cdot\left[\left(L_{3} / 2\right)^{2}+h^{2}\right]+m_{B} \cdot\left[\left(S p+D_{1} / 2\right)^{2}+h^{2}\right]+m_{C} \cdot\left[\left(L_{3} / 2\right)^{2}+h^{2}\right] \\
& I_{Y, 1}=I_{Y, 2}+m_{A} \cdot\left[\left(L_{2} / 2\right)^{2}+h^{2}\right]+m_{B} \cdot\left[\left(L_{2} / 2\right)^{2}+h^{2}\right]+m_{C} \cdot\left[\left(S p+D_{2} / 2\right)^{2}+h^{2}\right] \\
& I_{X Y, 1}=I_{X Y, 2}-m_{A} \cdot\left(L_{3} / 2 \cdot L_{2} / 2\right)-m_{B} \cdot\left[L_{2} / 2 \cdot\left(S p+D_{1} / 2\right)\right]-m_{C} \cdot\left[\left(S p+D_{2} / 2\right) \cdot L_{3} / 2\right]
\end{aligned}
$$




\section{REFERENCES}

1. Bothara, J.; Brzev, S. A Tutorial: Improving the Seismic Performance of Stone Masonry Buildings; First Edit.; Earthquake Engineering Research Institute: Oakland, California, United States of America, 2011; ISBN 9781932884487.

2. Casapulla, C.; Argiento, L.U. The comparative role of friction in local out-of-plane mechanisms of masonry buildings. Pushover analysis and experimental investigation. Eng. Struct. 2016, 126, 158-173.

3. Heyman, J. The stone skeleton. Int. J. Solids Struct. 1966, 2, 249-279.

4. Casapulla, C.; Maione, A.; Argiento, L.U. Seismic analysis of an existing masonry building according to the multi-level approach of the italian guidelines on cultural heritage. Ing. Sismica 2017, 34, 40-59.

5. Casapulla, C.; Giresini, L.; Lourenço, P.B. Rocking and Kinematic Approaches for Rigid Block Analysis of Masonry Walls: State of the Art and Recent Developments. 2017, 7, 69 .

6. Casapulla, C.; Maione, A. Critical Response of Free-Standing Rocking Blocks to the Intense Phase of an Earthquake. Int. Rev. Civ. Eng. 2017, 8, 1-10.

7. Sorrentino, L.; Masiani, R.; Decanini, L.D. Overturning of rocking rigid bodies under transient ground motions. Struct. Eng. Mech. 2006, 22, 293-310.

8. Casapulla, C. On the resonance conditions of rigid rocking blocks. Int. J. Eng. Technol. 2015, 7, 760-771.

9. Housner, G.W. The behavior of inverted pendulum structures during earthquakes. Bull. Seismol. Soc. Am. 1963, 53, 403-417.

10. Giresini, L.; Sassu, M. Horizontally restrained rocking blocks: evaluation of the role of boundary conditions with static and dynamic approaches. Bull. Earthq. Eng. 2017, 15, $385-410$.

11. AlShawa, O.; Liberatore, D.; Sorrentino, L. Dynamic One-Sided Out-Of-Plane Behavior of Unreinforced-Masonry Wall Restrained by Elasto-Plastic Tie-Rods. Int. J. Archit. Herit. 2019, 00, 1-18.

12. Giresini, L.; Fragiacomo, M.; Sassu, M. Rocking analysis of masonry walls interacting with roofs. Eng. Struct. 2016, 116, 107-120.

13. Giresini, L.; Casapulla, C.; Denysiuk, R.; Matos, J.; Sassu, M. Fragility curves for free and restrained rocking masonry façades in one-sided motion. Eng. Struct. 2018, 164, $195-213$.

14. Giresini, L. Design strategy for the rocking stability of horizontally restrained masonry walls. In Proceedings of the COMPDYN 2017 6th ECCOMAS Thematic Conference on Computational Methods in Structural Dynamics and Earthquake Engineering; $\mathrm{M}$. Papadrakakis, M.F., Ed.; Rhodes Island, Greece, 2017.

15. D'Ayala, D.; Speranza, E. Definition of Collapse Mechanisms and Seismic Vulnerability of Historic Masonry Buildings. Earthq. Spectra 2003, 19, 479-509.

16. Casapulla, C.; Maione, A.; Argiento, L.U.; Speranza, E. Corner failure in masonry buildings: An updated macro-modeling approach with frictional resistances. Eur. J. Mech. A/Solids 2018, 70, 213-225. 
17. Casapulla, C.; Maione, A. Experimental and Analytical Investigation on the Corner Failure in Masonry Buildings: Interaction between Rocking-Sliding and Horizontal Flexure. Int. J. Archit. Herit. 2018.

18. Casapulla, C.; Giresini, L.; Argiento, L.U. Non-linear static and dynamic analysis of rocking masonry facc1çades and corners using rigid macro-block modelling. Submitted to Earthq. Eng. Struct. Dyn. 2019.

19. Giresini, L.; Sassu, M.; Sorrentino, L. In situ free-vibration tests on unrestrained and restrained rocking masonry walls. Earthq. Eng. Struct. Dyn. 2018, 47, 3006-3025.

20. Sorrentino, L.; AlShawa, O.; Decanini, L.D. The relevance of energy damping in unreinforced masonry rocking mechanisms. Experimental and analytic investigations. Bull. Earthq. Eng. 2011, 9, 1617-1642.

21. Cattari, S.; Degli Abbati, S.; Ottonelli, D.; Sivori, D.; Spacone, E.; Camata, G. Task 4.1 Workgroup_Report di sintesi sulle attività svolte sugli edifici in muratura monitorati dall'Osservatorio Sismico delle Strutture, Linea Strutture in Muratura.; 2017;

22. Solarino, F.; Oliveira, D. V; Giresini, L. Wall-to-horizontal diaphragm connections in historical buildings: a state-of-the-art review. Submitted to Eng. Struct. 2019.

23. Giresini, L.; Fragiacomo, M.; Lourenço, P.B. Comparison between rocking analysis and kinematic analysis for the dynamic out-of-plane behavior of masonry walls. Earthq. Eng. Struct. Dyn. 2015, 44, 2359-2376.

24. MathWorks Matlab R2016b Available online: https://it.mathworks.com/products/matlab.html.

25. Ferrero, C.; Lourenco, P.; Calderini, C. 2016-2017 Central Italy Earthquake: Seismic Assessment of "Pietro Capuzi" School in Visso (Marche). In Proceedings of the The 9th International Conference on Computational Methods (ICCM2018); 2018.

26. Housner, G.W. The behavior of inverted pendulum structures during earthquakes. Bull. Seismol. Soc. Am. 1963, 53, 403-417.

27. Casapulla, C., Giresini, L., Sassu, M., Lourenço, P.B. Rocking and kinematic approaches of masonry walls: state of the art and recent developments. Buildings 2017. 